\title{
Solid-State Conversion of Magnesium Waste to Advanced Hydrogen-Storage Nanopowder Particles
}

\author{
Mohamed Sherif El-Eskandarany ${ }^{1, *}$, Naser Ali ${ }^{1}{ }^{10}$ and Sultan Majed Al-Salem ${ }^{2}$ (]) \\ 1 Energy and Building Research Center, Kuwait Institute for Scientific Research, Safat 13109, Kuwait; \\ nmali@kisr.edu.kw \\ 2 Environment \& Life Sciences Research Centre, Kuwait Institute for Scientific Research, Safat 13109, Kuwait; \\ ssalem@kisr.edu.kw \\ * Correspondence: msherif@kisr.edu.kw
}

Received: 10 May 2020; Accepted: 27 May 2020; Published: 28 May 2020

\begin{abstract}
Recycling of metallic solid-waste (SW) components has recently become one of the most attractive topics for scientific research and applications on a global scale. A considerable number of applications are proposed for utilizing metallic SW products in different applications. Utilization of SW magnesium (Mg) metal for tailoring high-hydrogen storage capacity nanoparticles has never been reported as yet. The present study demonstrates the ability to produce pure Mg ingots through a melting and casting approach from Mg-machining chips. The ingots were used as a feedstock material to produce high-quality Mg-ribbons, using a melting/casting and spinning approaches. The ribbons were then subjected to severe plastic deformation through the cold rolling technique. The as-cold roll $\mathrm{Mg}$ strips were then snipped into small shots before charging them into reactive ball milling. The milling process was undertaken under high-pressure of pure hydrogen gas $\left(\mathrm{H}_{2}\right)$, where titanium balls were used as milling media. The final product obtained after $100 \mathrm{~h}$ of milling showcased excellent nanocrystalline structure and revealed high hydro/dehydrogenation kinetics at moderate temperature $\left(275^{\circ} \mathrm{C}\right)$. The present study shows that primer cold rolling of Mg-strips before reactive ball milling is a necessary step to prepare ultrafine magnesium hydride $\left(\mathrm{MgH}_{2}\right)$ nanopowders with advanced absorption/desorption kinetics behavior. These ultrafine powders with their nanocrystalline structure are believed to play an important role in effective gas diffusion process. Moreover, the fine titanium particles came from the ball-powder-ball collisions and introduced to the $\mathrm{Mg}$ matrix have not only acted as micro-scaled milling media, but they played a vital catalyzation role for the process.
\end{abstract}

Keywords: solid waste; magnesium; milling; metal waste; magnesium hydride

\section{Introduction}

\subsection{Background}

\subsubsection{Solid-Waste Management}

Historically, waste is stigmatized as an undesired material, which must be disposed of after its primary use. It was believed that solid waste (SW) management is a difficult and expensive task that requires prolonged time-consuming procedures. In the present day, significant strides are achieved in dealing with SW components of various types to overcome concerns with their recycling and recovery procedures [1,2]. SW of metallic origin and alloys is a prime example of it originating from scrap automobiles and the industrial sector [3-6]. Global interest in recycling ferrous and nonferrous metal alloys including magnesium $(\mathrm{Mg})$ metal, has received great attention as of late. This is due to their favorable engineering properties [7-9]. Its lightness, excellent flexibility and abundance as a natural 
resource, make $\mathrm{Mg}$ a particularly desired material, especially when the overall strength of a material is desired [10].

\subsubsection{Nano-Mg as a Solid-State Hydrogen Storage Materials}

In addition to the useful applications of $\mathrm{Mg}$ in a wide range of industrial sectors (e.g., automotive, aerospace, medical, and electronics applications) it has been considered as a promising candidate material for solid-state hydrogen storage applications [11-14]. Metallic Mg possesses a unique combination of high gravimetric $(7.60 \mathrm{wt} \%)$ and volumetric $(110 \mathrm{~g} / \mathrm{L})$ hydrogen storage capacities, as well as a good cyclability [15]. It should be noted that tetragonal magnesium hydride $\left(\mathrm{MgH}_{2}\right)$ in $\beta$-phase is a very stable compound in a thermodynamic sense, requiring elevated temperatures to decompose $\left(>350^{\circ} \mathrm{C}\right)$ [14]. It also exhibits a high value of apparent activation energy $\left(\mathrm{E}_{\mathrm{a}}>130 \mathrm{~kJ} / \mathrm{mol}\right)$ [16]. Below this temperature, $\mathrm{MgH}_{2}$ shows very slow hydrogenation/dehydrogenation kinetics [17].

For $\mathrm{MgH}_{2}$ to be employed in fuel cell applications, it must undergo severe treatment processes dedicated to accelerating its inherently poor kinetic behavior, in order to reduce its activation energy of decomposition [18-20]. Within the last three decades, different options were proposed to improve the hydrogen storage behavior of $\mathrm{Mg} / \mathrm{MgH}_{2}$. These options include severe plastic deformation (SPD), high-energy ball milling (HEBM), cold-rolling (CR), equal channel angular pressing (ECAP), and high-pressure torsion (HPT) [21-23].

Doping $\mathrm{Mg} / \mathrm{MgH}_{2}$ powders with catalytic agents is a different approach used to increase the hydrogenation/dehydrogenation kinetic of $\mathrm{MgH}_{2}$. Since the 1990s, a wide range of pure transition metals (TM) have been used at different concentrations to improve the behavior of $\mathrm{Mg} / \mathrm{MgH}$ powders. Due to their superior capability for hydrogen splitting (dissociation) and re-combination, many of these metals exerted remarkable beneficial effects in modifying hydrogen storage properties of $\mathrm{Mg} / \mathrm{MgH}_{2}$. Elemental nickel (Ni), titanium (Ti), vanadium (V), and manganese (Mn) metals [24,25], as well as their alloys [26-30] were successfully employed to improve the hydrogen storage behavior of $\mathrm{MgH}_{2}$ powders. In addition to the metals and their alloys, compounds and metastable catalytic agents, metal-oxides (e.g., $\mathrm{Nb}_{2} \mathrm{O}_{5}$ [31,32], $\mathrm{Cr}_{2} \mathrm{O}_{3}$ [33], and $\mathrm{TiO}_{2}$ [34], -carbides (e.g., $\mathrm{SiC}$ [35], and $\mathrm{TiC}$ [36]), -hydrides (e.g., $\mathrm{TiH}_{2}$ [37], $\mathrm{LaH}_{3}$ [38], and $\mathrm{NbH}$ [38]), and carbon-based nanomaterials such as carbon nanotubes [39], and graphene nanofibers [40].

\subsection{Aim of the Present Study}

The present study focuses in part on the possibility of utilizing SW-Mg machining chips with the aim of fabricating high-quality $\mathrm{Mg}$ nanopowder particles, using a multistage process of melting/casting, melt spinning (MS) and CR. The effect of the plastic deformation generated by CR on the grain size of Mg-ribbons was studied as a function of the number of passes, in the range between 0 to 150 passes. The as-refined pure $\mathrm{Mg}$-metal was used as feedstock materials for synthesizing nanocrystalline $\mathrm{MgH}_{2}$ powders through a reactive ball milling (RBM) approach. Moreover, this study has investigated the effect of using pure Ti-ball milling media on the hydrogenation/dehydrogenation kinetics of $\mathrm{MgH}_{2}$ upon milling for different RBM times. To the best of our knowledge, there exist various studies that show different methods of recycling $\mathrm{Mg}$ [7-9], but no studies report as of yet the possibility of preparing $\mathrm{Mg} / \mathrm{MgH}_{2}$ nanopowder particles from an SW feedstock.

\section{Materials and Methods}

\subsection{The Feedstock Materials}

For the purpose of the present study, a batch of $10 \mathrm{~kg}$ of pure $(99.5 \mathrm{wt} \%) \mathrm{Mg}$ chips (25-35 $\mathrm{mm}$ in length and $\sim 20 \mathrm{~mm}$ in thickness) were acquired from Shanghai Xinglu Chemical Technology Co., Ltd., Shanghai, China, and used as feedstock materials (Figure 1a). The received chips were firstly sonicated in a cold-acetone bath for $10 \mathrm{~min}$ to ensure removing all machining oil coolants from their surfaces. The chips were then rinsed with pure ethanol before drying in an oven at $180{ }^{\circ} \mathrm{C}$ for a continuous 
period of $18 \mathrm{~h}$. This primer-treating step was necessary to remove all of the undesired hydrocarbon contaminants from the chip's surfaces. A $300 \mathrm{~g}$ amount of oil-free chips was then placed in a graphite crucible and placed in a conventional melting/casting machine (Figure 1b).

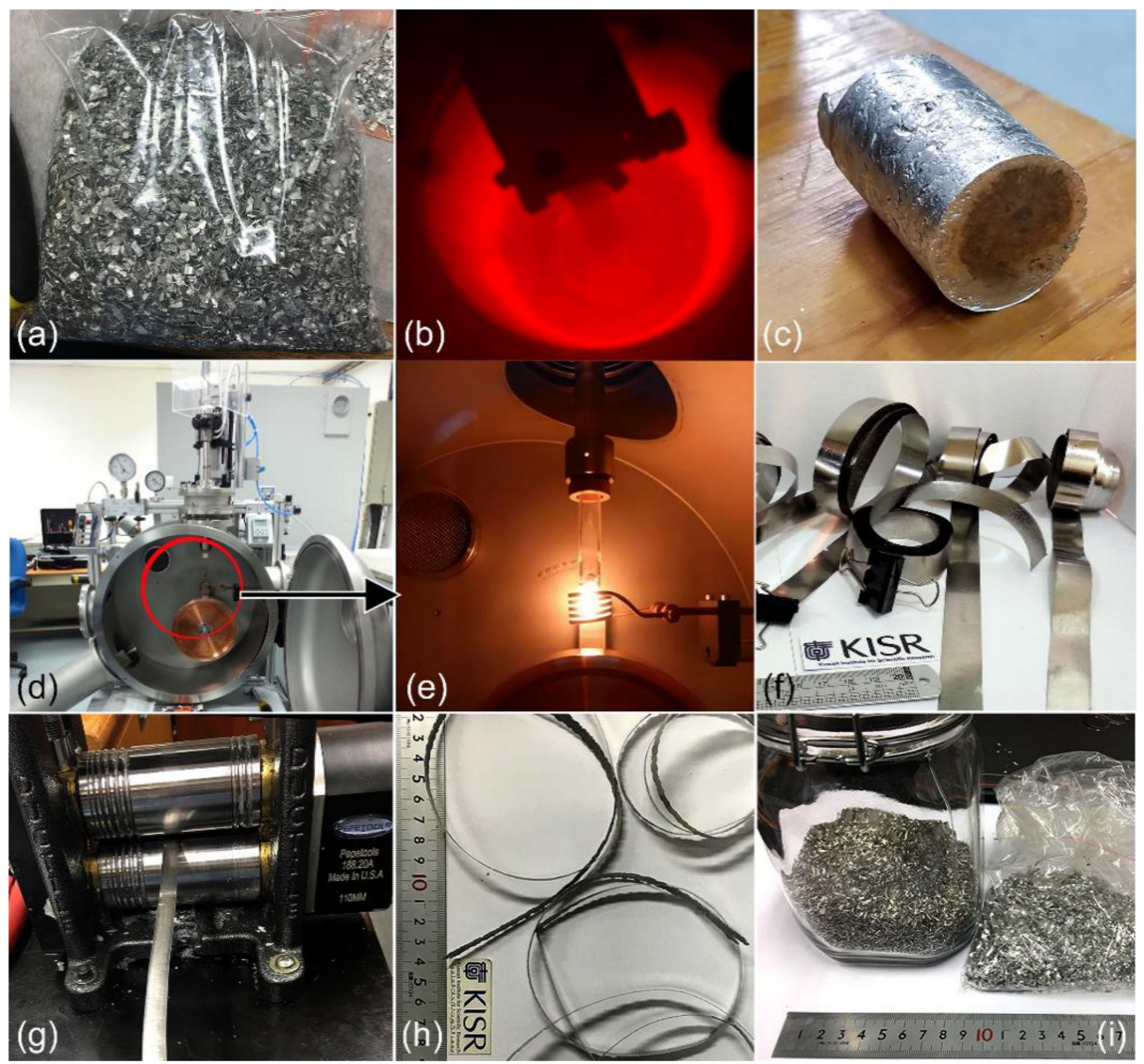

Figure 1. Conversion of solid-waste (SW) Mg machining chips into microscaled Mg-shots. (a) as-received SW-Mg chips, (b) melting and casting processes, (c) as-casted pure (99.95 wt\%) Mg-ingot, (d), (e) melt spinning (MS) process, (f) as-MS Mg-ribbons, (g) cold rolling (CR) process, (h) as-CR Mg-strips, and (i) as-snipped $\mathrm{Mg}$-shots.

The induction melting section was firstly evacuated to the level of $10^{-5}$ bar before being filled with pure argon $(\mathrm{Ar}, 99.99 \mathrm{wt} \%)$ gas. Then, the melting process was performed at $750{ }^{\circ} \mathrm{C}$ for three continuous cycles. During the melting process, $100 \mathrm{~mL}$ of Ar gas was introduced frequently, in order to ensure the purification of the molten $\mathrm{Mg}$. Towards the end of the melting procedure, the bottom part of the graphite crucible was opened, where the molten metal was sunk into a cylindrical graphite crucible at a temperature of almost $400^{\circ} \mathrm{C}$. The system was kept for $9 \mathrm{~h}$ before opening it to remove the $\mathrm{Mg}$ ingot from the crucible (Figure 1c). The elemental analysis of the cast- $\mathrm{Mg}$ indicated that the material was ultra-pure (99.88 wt \%) with less than $0.11 \mathrm{wt} \%$ oxygen and $0.01 \mathrm{wt} \%$ carbon, as characterized by inert gas fusion, and thermal conductivity detection test techniques, respectively.

About $5 \mathrm{~g}$ of small pieces $\left(\sim 30-40 \mathrm{~mm}^{3}\right)$ of the as-cast $\mathrm{Mg}$ ingot were inserted in a quartz tube and fixed in PA 500 melt spinner (MS) machine, provided by Edmund Bühler, Germany (Figure 1d). A single $\mathrm{Cu}$-wheel drum, rotated at $5000 \mathrm{rpm}$ was used to provide a rapid quenching of the melt. The MS process was first evacuated to the level of $10^{-6}$ before introducing pure helium (99.99 wt $\left.\%\right)$ gas to the quartz-crucible and MS-chamber. Then, the crucible was pressurized with 3 bar of He gas, and the chamber was maintained under 0.8 bar of He. The induction melting was taken place at $750{ }^{\circ} \mathrm{C}$ (Figure 1e). The molten Mg-fluid was forced to travel into the hole in the bottom of the quartz-crucible upon pressurizing the crucible with an extra 2 bar of He gas. The Mg-droplets passed from the hole 
were rapidly quenched with a very high cooling rate generated by the rotated $\mathrm{Cu}$-drum. The end product of MS-Mg was in the shape of ribbons of $\sim 0.5 \mathrm{~mm}$ in thickness, and $\sim 300 \mathrm{~cm}$ in length, as shown in Figure 1f.

The as-MS ribbons were cut into smaller strips of almost $20 \mathrm{~cm}$ in length and then subjected to $\mathrm{CR}$ for 150 passes, using a conventional two-tool steel drum cold roller (Figure 1g). The strips were warm pressed at $150{ }^{\circ} \mathrm{C}$ for $5 \mathrm{~min}$ after every 10 passes using a two -plate warm press to avoid brittleness in the Mg strips that occurred during the CR process. The as-CR Mg strips were elongated by approximately $112 \%$ after the completion of 150 passes (Figure $1 \mathrm{~h}$ ). The average thickness of the as-CR Mg strips was reached to $108 \mu \mathrm{m}$ after CR. The CR Mg-strips were cut into short ribbons of approximately 4 to $10 \mathrm{~mm}$ in length, $0.5 \mathrm{~cm}$ in thickness. These snipped strips were simply cleaned with acetone and ethanol, and then dried in an oven at $150{ }^{\circ} \mathrm{C}$ overnight. The as-snipped $\mathrm{Mg}$ shots were sealed under He gas atmosphere and kept in an argon glove box (Figure 1i).

\subsection{Preparation of $\mathrm{MgH}_{2}$ Nanopowder Particles}

Figure 2 summarizes the experimental procedure performed for preparing nanodimensional $\mathrm{MgH}_{2}$ particles, using the RBM technique. We firstly prepared a large number of pure Ti-balls using an arc melter (Edmund Bühler, Germany). In this process, sponge Ti was melted under pure He (99.99 wt\%) gas atmosphere in a Cu-hearth. The Ti pieces were then remelted again in the arc melter to produce nearly spherical balls with diameters of $11 \mathrm{~mm}$ to $13 \mathrm{~mm}$, as shown in Figure 2a.
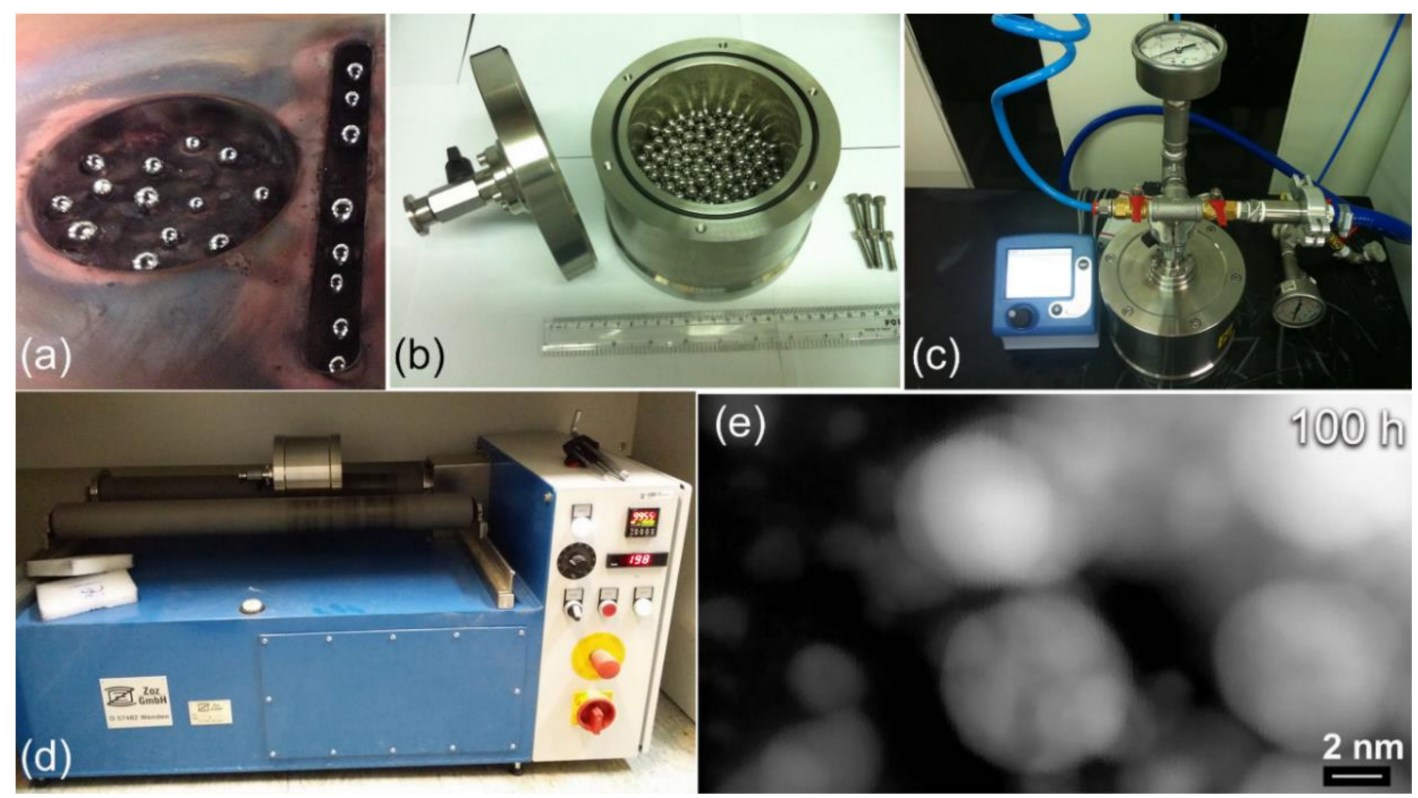

Figure 2. Reactive ball milling (RBM) process, employed for preparing nanocrystalline $\mathrm{MgH}_{2}$ powder particles. (a) Preparing of Ti balls milling media with arc melting process, (b) tool-steel milling vial, charged with Mg-shots, (c) the milling vial was pressurized with 15 bar of hydrogen gas, and (d) the RBM process was carried out at room temperature, using a roller mill. The scanning transmission electron (STEM) image of $\mathrm{CR} \mathrm{MgH}_{2}$-ribbons obtained after $100 \mathrm{~h}$ of $\mathrm{RBM}$ is displayed in (e).

An amount of $50 \mathrm{~g}$ of $\mathrm{Mg}$ shots and a number of 250 Ti-balls were charged into a cylindrical vial made of tool-steel and sealed together in a glove box (UNILAB Pro Glove Box Workstation, mBRAUN, Germany) under pure (99.99 wt\%) He gas atmosphere, as shown in Figure $2 \mathrm{~b}$. The ball-to-powder weight ratio was 36:1. The sealed vial was then evacuated to the level of $10^{-3}$ bar or better before pressurized with 15 bar of pure (99.999 wt\%) $\mathrm{H}_{2}$ gas, as displayed in Figure 2c.

The vial was mounted on the roller of a tumbling mill, rotated at $300 \mathrm{rpm}$ (Figure 2d). The RBM process was conducted at room temperature, using a milling speed of $250 \mathrm{rpm}$. To understand the 
mechanism of mechanically-induced gas-solid reaction taking place during the RBM process, the tumbling mill was interrupted after selected milling time $(3,6,12.5,18,25,37.5,50,100$, and $150 \mathrm{~h})$, where the milled powders were completely discharged from the vial in the He-glove box. The RBM process was resumed with fresh batches of CR Mg-strips, using the same milling parameters. The scanning transmission electron (STEM) image of the powders for the end-product sample ( $100 \mathrm{~h}$ of RBM) is displayed in Figure 2e. The powders after this final milling stage composited of nanoscaled spherical particles, with particle size laid in the range from $\sim 2 \mathrm{~nm}$ to $6 \mathrm{~nm}$ in diameter, as shown in Figure 2e.

\subsection{Sample Characterizations}

\subsubsection{Crystal Structure}

The crystal structures of all samples were investigated by X-ray diffraction (XRD) with CuK $\alpha$ radiation, using $9 \mathrm{~kW}$ Intelligent $X$-ray diffraction system, provided by SmartLab (Rigaku, Japan). The local structure of the synthesized materials was studied by $200 \mathrm{kV}$-field emission high-resolution transmission electron microscopy/scanning transmission electron microscopy (HRTEM/STEM) supplied by JEOL-2100F (Tokyo, Japan), and equipped with energy-dispersive X-ray spectroscopy (EDS) supplied by Oxford Instruments, (Abingdon, UK). A Cryo Ion Slicer Machine (IB-09060CIS) supplied by JEOL-2100F, (Tokyo, Japan) was used to prepared TEM samples of as-CR Mg strips.

\subsubsection{Morphology and Elemental Analysis}

The morphological characteristics of the milled and consolidated samples were investigated by means of field-emission scanning electron microscope (FE-SEM), using $15 \mathrm{kV}-\mathrm{JSM}-7800 \mathrm{~F}$, JEOL, (Tokyo, Japan). The local elemental analysis was investigated by EDS (Oxford Instruments, Abingdon, UK) system interfaced with the FE-SEM.

\subsubsection{Thermal Stability}

Differential scanning calorimeter (DSC), provided by Setaram Instrumentation (Caluire, France)—was employed to investigate the decomposition temperature of $\mathrm{MgH}_{2}$ powder samples that were obtained after different RBM time.

\subsubsection{Hydrogenation/Dehydrogenation Kinetics Behavior}

The absorption/desorption kinetics of $\mathrm{MgH}_{2}$ powders obtained after different $\mathrm{RBM}$ times were investigated at $275^{\circ} \mathrm{C}$ by means of Sievert's method, using PCT-Pro2000 (Setaram Instrumentation, Caluire, France). The applied hydrogenation and dehydrogenation pressures were 10 bar and 400 mbar, respectively.

\section{Results and Discussion}

\subsection{Morphology and Crystal Structure}

\subsubsection{CR Mg-Ribbons}

TEM image in a low-magnification bright field (BF) mode for the planner view of a polished sample of as-MS Mg ribbon is displayed in Figure 3a. The sample composited of a mixture of largeand medium-sized grains, with an average grain size of $\sim 480 \mathrm{~nm}$ (Figure 3a). Initially, Mg-ribbons revealed twin free-grain boundaries with no indication latter of lattice imperfections (Figure 3a). The XRD pattern of the as-MS Mg-ribbons is displayed in Figure 4a. The sample exhibited sharp Bragg peaks corresponding to hcp-Mg (PDF 00-004-0770) without evidence of any Bragg-peaks' mismatches (Figure 4a). This could be attributed to the absence of lattice imperfections in the MS-Mg ribbons. 

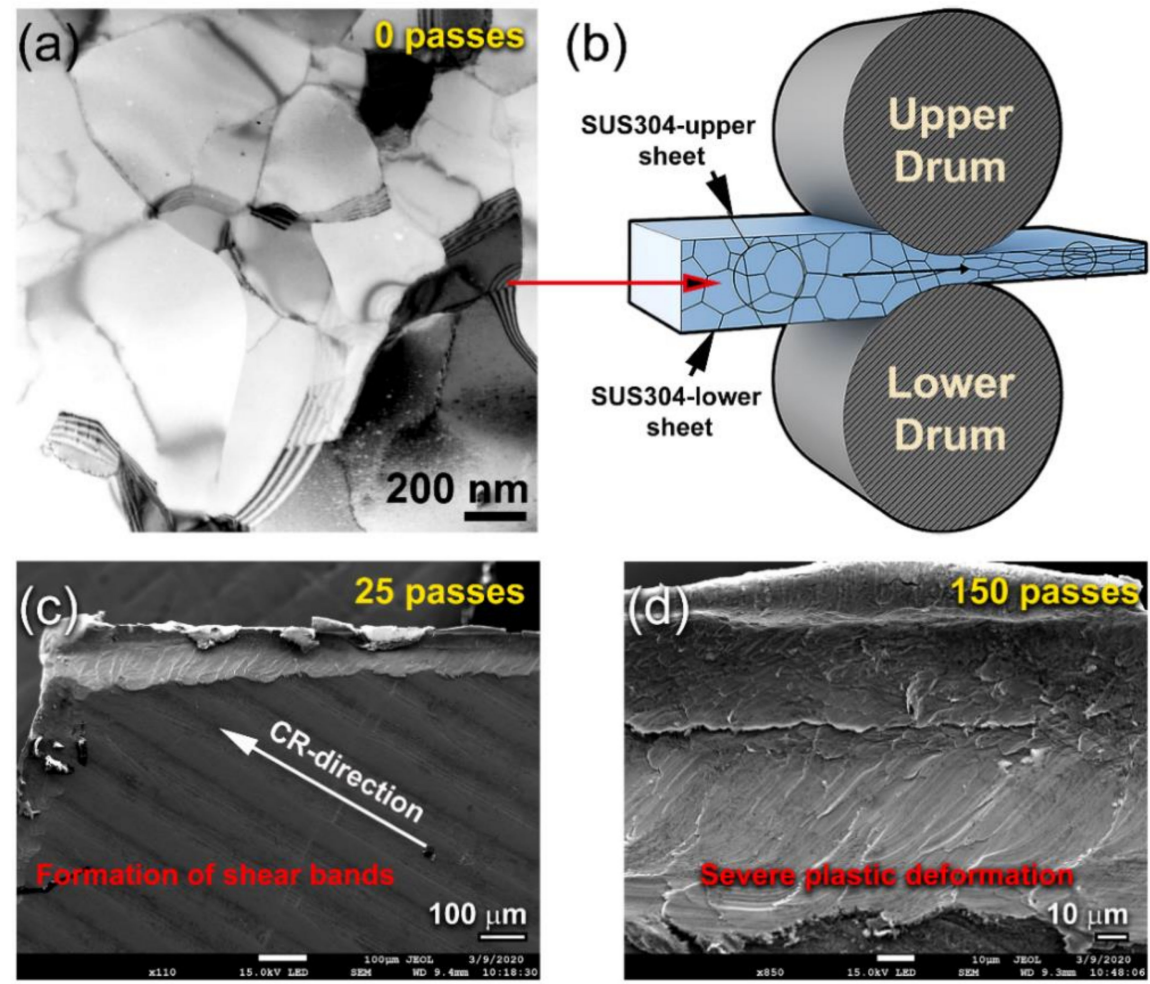

Figure 3. (a) Low magnification transmission electron microscopy (TEM)-BFI of as-MS Mg-ribbon, and (b) schematic illustrates the $\mathrm{CR}$ process of Mg-chips. The low magnification field-emission scanning electron microscope (FE-SEM) micrographs of Mg-ribbons after CR for 25 and 150 passes are displayed in (c) and (d), respectively.

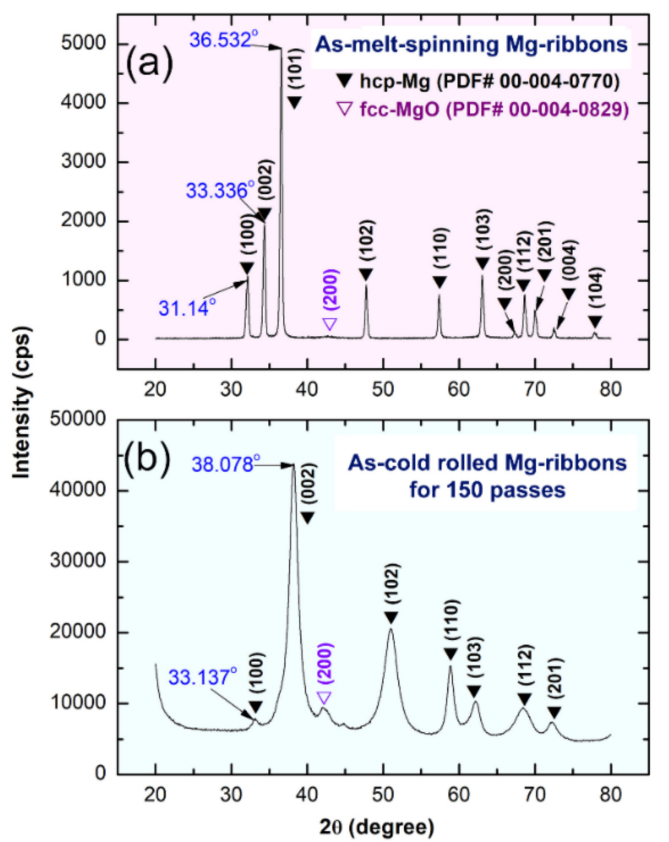

Figure 4. X-ray diffraction (XRD) patterns of Mg-ribbons after CR for (a) 0 passes, and (b) 150 passes.

When the ribbons were cold-rolled for 25 passes, they revealed obvious micro-intimated bands that have developed as a result of the shear stresses applied to them during the CR process (Figure 3c). This was confirmed by the BF-TEM image of a cross-section view of the as-CR Mg ribbons obtained after 25 passes that revealed lattice imperfections beyond the atomic level, as indexed by the extrinsic 
dislocations presented in Figure 5a. Severe plastic deformation was realized upon increasing the CR passing time to 150. This is implied by the formation of ultrafine bent shear bands with less than 5 $\mu \mathrm{m}$ in width, as displayed in Figure 3d. In contrast to the initially studied MS-Mg ribbons, two major hcp-Mg Bragg peaks, namely, (100) and (002), were shifted to the high-angle side, where the major crystallographic plane (101) had completely disappeared in the sample obtained after 150-passes of CR (Figure 4b). This implies a severe lattice imperfection conducted during the CR process [41] and the development of a very high level of the plane (002) of fiber texture [42]. The significant broadening that observed in the Bragg peaks for the sample obtained after 150 passes of CR (Figure 4 b) was attributed to the internal strain related to the existence of a high dislocation density and grain refinement.

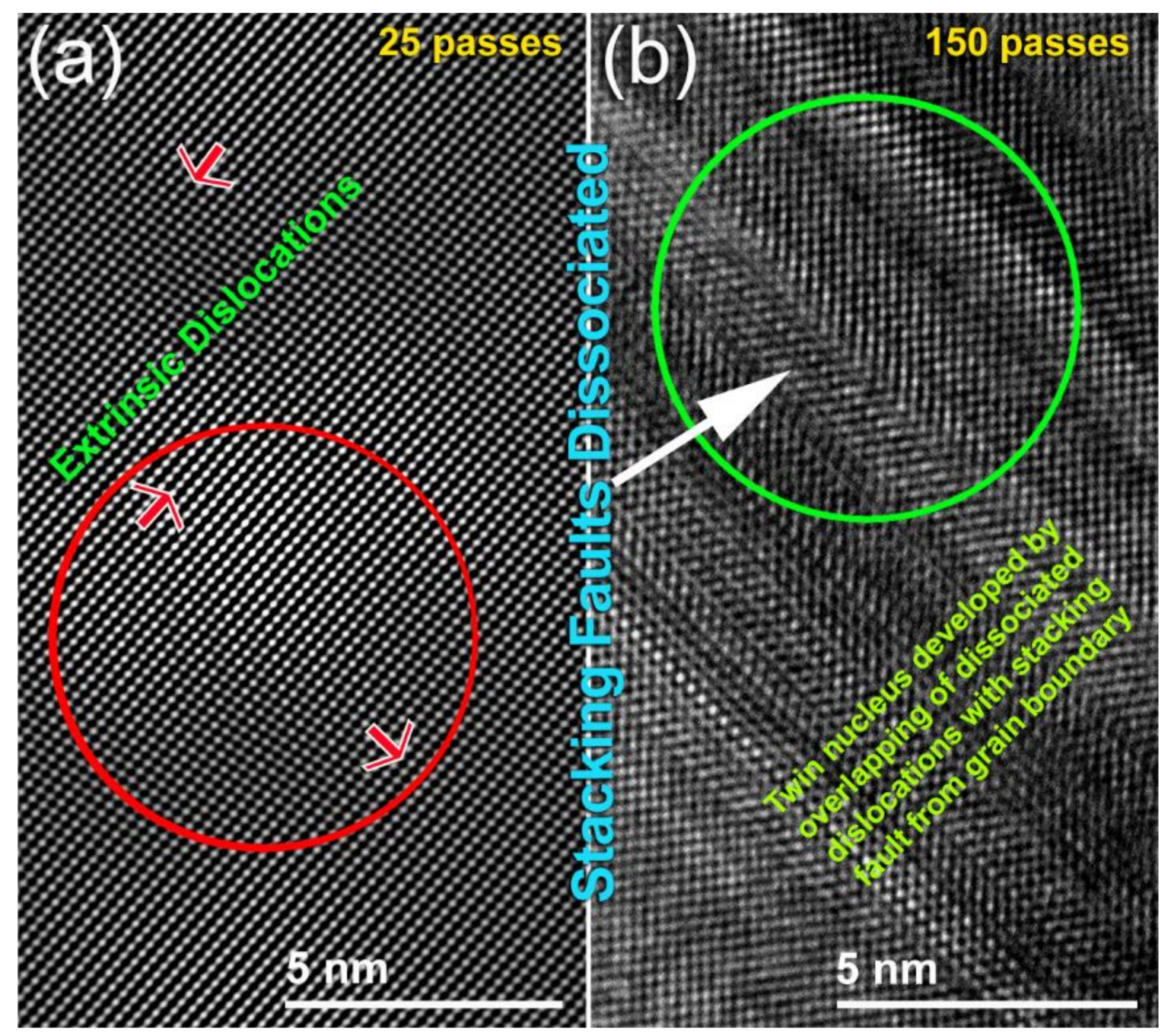

Figure 5. Atomic resolution FE-TEM images of Mg-ribbons after CR for (a) 25 passes, and (b) 150 passes.

After this final stage of CR (150 passes), the sample possessed twin nuclei that overlapped with dissociated dislocation and stacking faults from the grain boundary, as as seen in Figure $5 \mathrm{~b}$. This could be explained by the deformation that developed in hcp-metals which are typically accommodated by twinning and basal slip deformation mechanisms [43]. Moreover, the CR ribbons exhibited different types of twins, such as V-shaped, and deformation twins, as illustrated in Figure 5b. Accordingly, this twinning that developed during the CR process is believed to be responsible for the formation of different amounts of (002) texture, as suggested by Jorge et al. [42]. 


\subsubsection{Reactive Ball Milling of Mg Powders}

Figure 6a depicts a schematic illustration of the tumbler ball mill, used in this work to perform a solid-state hydrogenation reaction between $\mathrm{Mg}$ and hydrogen gas. In the reactive ball milling (RBM) process, the starting CR Mg-shots, which are composed of large pieces (500 $\mu \mathrm{m}$ to $2000 \mu \mathrm{m}$ ) (Figure 7a) are in contact with the abrasive forces generated by the Ti balls-milling media (Figure 6a,b). After $30 \mathrm{~min}$ of the RBM process, the Mg metal-pieces tended to agglomerate into larger pieces, have almost $3500 \mu \mathrm{m}$ in size (Figure $7 \mathrm{~b}$ or Figure $8 \mathrm{a}$ ). The agglomeration, which was happened during the first stage of RBM was attributed to the successive cold-welding of the ductile Mg-metal [44]. This resulted from the impact forces generated upon balls-particles-ball collision, as illustrated in Figure $6 \mathrm{~b}$.

The useful kinetic energy in tumbling mill applied to the Mg-shots can be summarized by the following means (1) collision between the balls and the particle; (2) pressure loading of particles pinned between milling media or between the milling media and the liner; (3) impact of the falling milling media; (4) shear and abrasion caused by dragging of particles between moving milling media; and (5) shock-wave transmitted through crop load by falling milling media [45].

In general, the RBM process for the formation of $\mathrm{MgH}_{2}$ powder particles can be classified into three consequent stages; (1) defragmentation; (2) gas-solid reaction; and (3) refining stages, as presented in Figure 8a. After $1 \mathrm{~h}$ of RBM time, the impact led to deform the ductile Mg-particles to yield aggregates with plate-like morphology, as presented in Figure 7c. However, the sample obtained after this stage of milling revealed wide size distribution, extended from a few $\mathrm{mm}$ to several $\mathrm{mm}$ in size, as shown in Figure 8b. Application of the impact forces to the particles led to increasing their hardness due to work hardening. Accordingly, the Mg-particles became brittle, as indicated by the cracks and cleavage fractures indexed in Figure 7c. Further RBM time (3 to $12.5 \mathrm{~h}$ ) led to severe fragmentation of $\mathrm{Mg}$-particles, where the $\mathrm{MgO}$-crust coated the particles were gradually removed with increasing the RBM time, as presented in Figure 7d,e. This milling step led to creating fresh-Mg surfaces ready to react with hydrogen milling atmosphere [46]. We should emphasize that the fine Ti-particles indexed in Figure 7e resulted from the erosion that took place between Ti balls (milling media) during the milling process. Such fine micro-milling media are believed to play a vital role in reducing the $\mathrm{Mg}$ particle size and to enhance the hydrogenation reaction during the RBM process [47].

Further RBM time $(25 \mathrm{~h}$ ) led to performing significant disintegration of the brittle Mg-powders (Figure 7f) to obtain finer particles (Figure 7f) with sizes ranging from 5 to $65 \mu \mathrm{m}$ in diameter, as presented in Figure 8a. At the second stage of milling (gas-solid reaction stage), the XRD patterns of the sample obtained after $25 \mathrm{~h}$ of RBM revealed a new set of Bragg-peaks (Figure 9a) that could not be identified for the sample obtained after 150 passes of CR (Figure 4b). The analysis of these new diffraction lines indicated that the sample obtained after $25 \mathrm{~h}$ of RBM time composited of $\beta-\mathrm{MgH}_{2}$, $\gamma-\mathrm{MgH}_{2}$, as well unreacted hcp-Mg metal, and phases, as displayed in Figure 9a.

After $50 \mathrm{~h}$ of continuous $\mathrm{RBM}$, microscaled $\mathrm{MgH}_{2}$ powder particles $(\sim 8 \mu \mathrm{m})$ were obtained, as shown in Figure $7 \mathrm{~g}$ or Figure 8a. These formed fine particles tended to be agglomerated due to van der Waals forces to form larger aggregates with apparent sizes reached to $160 \mu \mathrm{m}$ in diameter, as displayed in Figure $7 \mathrm{~g}$. Increasing the RBM time to $75 \mathrm{~h}$ led to an increase of the fresh surfaces of the unreacted $\mathrm{Mg}$ powders that consequently reacted with the hydrogen atoms to form $\mathrm{MgH}_{2}$ powders. Meanwhile, increasing the RBM time led to further powder refining, as indicated by the dramatic reduction in the powders particle size of the obtained after $75 \mathrm{~h}$ of RBM (less than $200 \mathrm{~nm}$ in diameter), as presented in Figure 7h or Figure 8a. These nanoscaled powder particles were aggregated to form microscaled particles $(\sim 2.3 \mu \mathrm{m}$ in diameter) after $100 \mathrm{~h}$ of RBM, as presented in Figure 7i or Figure 8a.

The XRD patterns of the powder particles obtained after $100 \mathrm{~h}$ of RBM revealed the formation of a single $\beta-\mathrm{MgH}_{2}$ phase coexisted with small molecular fractions of metastable of $\gamma-\mathrm{MgH}_{2}$ phase, as displayed in Figure 9b. It is worth noting that the Bragg-peaks related to unreacted $\mathrm{Mg}$-metal had already disappeared, suggesting the completion of the RBM process (Figure 9b). The formation of nanoscaled $\mathrm{MgH}_{2}$ powder particles was confirmed by HRTEM, which indicated the formation of nano-dimensional particles with $\sim 12 \mathrm{~nm}$ in diameter, as presented in Figure $9 \mathrm{c}$. The filtered image taken 
for the zone shown in Figure 9c, displayed the lattice fringe image of tetragonal- $\mathrm{MgH}_{2}(\beta$-phase $)-$ in projection $<110>$ direction (Figure $9 \mathrm{~d}$ ). The measured interplanar lattice -spacing distance (d), which was measured and found to be $0.3188 \mathrm{~nm}$ (Figure $9 \mathrm{~d}$ ) matched well with the reported value $(0.3185 \mathrm{~nm})$ of $\beta-\mathrm{MgH}_{2}$ (PDF file\# 01-080-4431). Scanning transmission electron microscope, STEM (Figure 9e) was used together with X-ray EDS mapping technique to understand the distribution of elemental Ti-metal nanoparticles in the $\mathrm{MgH}_{2}$ matrix.
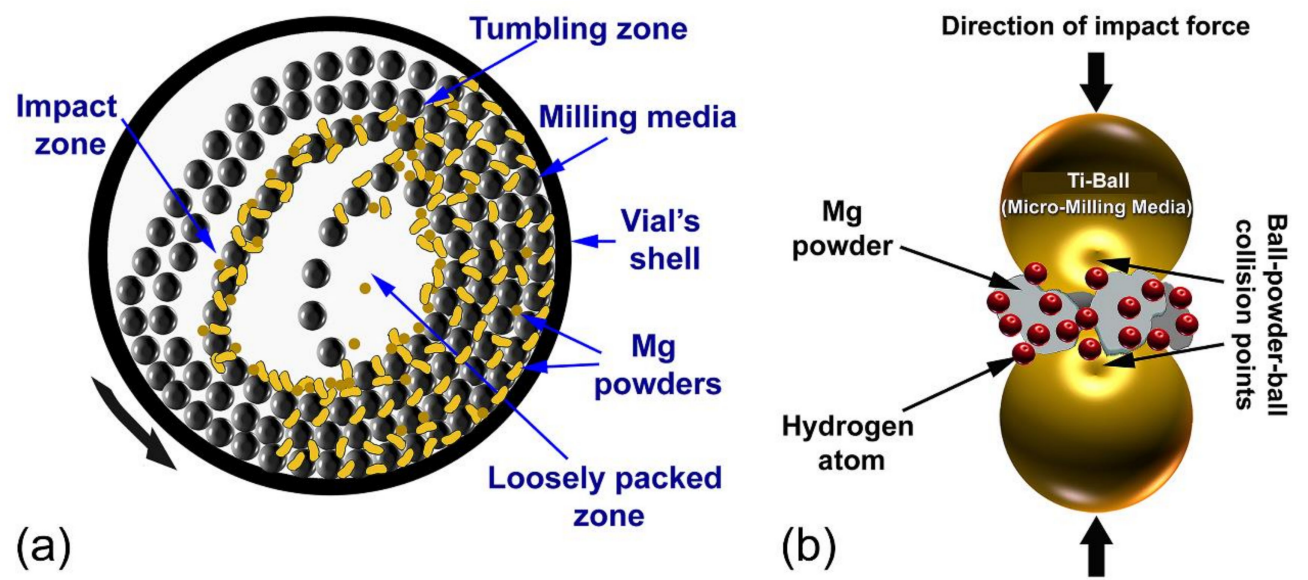

Figure 6. Schematic presents the (a) movement of the balls and materials (Mg shots and powders) inside a sealed cylindrical vial, which is pressurized with 15 bar of $\mathrm{H}_{2}$ gas, and (b) ball-powder-ball collision during RBM process, using a tumbler ball mill.
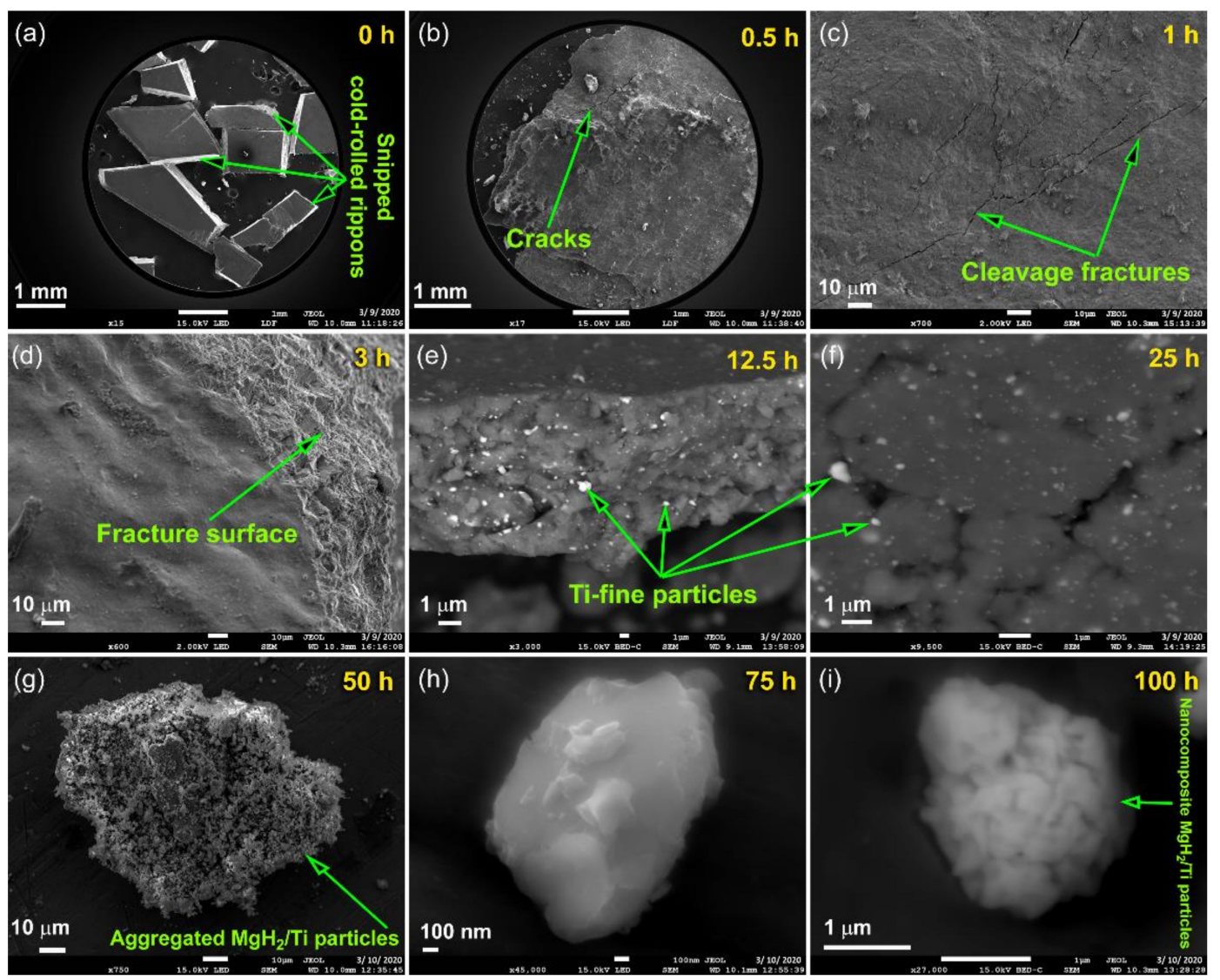

Figure 7. FE-SEM images of Mg-strips obtained after CR for 150 passes and then RBM for (a) 0, (b) 0.5, (c) 1, (d) 3, (e) 12.5, (f) 25, (g) 50, (h) 75, and (i) $100 \mathrm{~h}$ of RBM time. 

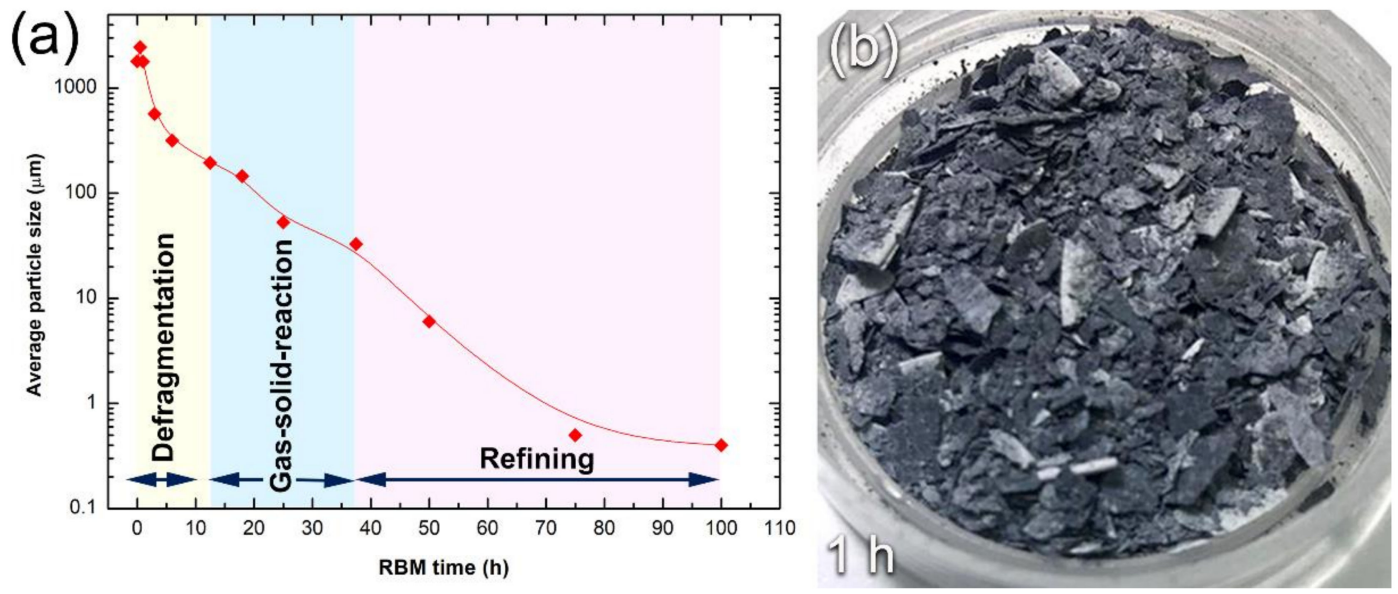

Figure 8. (a) Particle size distribution of as-CR Mg strips during the different stages of milling named; defragmentation; gas-solid reaction; and refining stages, and (b) an optical image of the sample obtained after $0.5 \mathrm{~h}$ RBM.
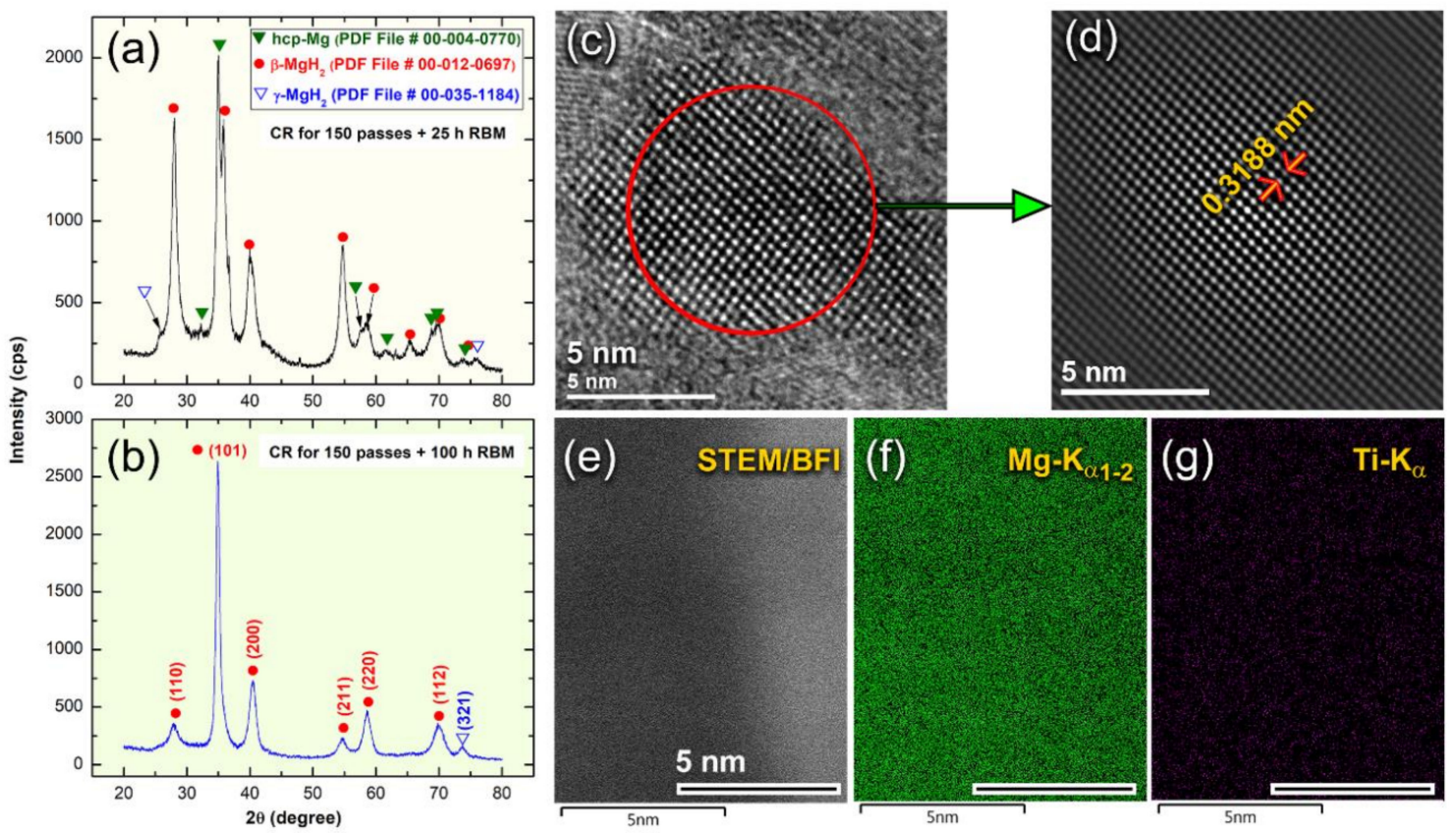

Figure 9. XRD patterns of Mg-ribbons obtained after CR for 150 passes then RBM for (a) 25, and (b) $100 \mathrm{~h}$ of RBM time. The high-resolution transmission electron microscopy/scanning transmission electron microscopy (HRTEM) image of the powder particles obtained after $100 \mathrm{~h}$ of RBM is displayed in (c), where a filtered atomic-resolution TEM image taken from the indexed zone shown in (c) is presented in (d). Elsewhere, the STEM/BFI image of the powder obtained after 100 of RBM is displayed in (e) together with the related X-ray energy-dispersive X-ray spectroscopy (EDS) elemental analysis of (f) $\mathrm{Mg}$ and (g) Ti.

The powder particles obtained at this final stage of RBM $(100 \mathrm{~h})$ possessed a fine structure beyond the sub-nano level (Figure 9e). The overall $\mathrm{MgH}_{2}$ matrix coexisted with ultrafine lenses of metallic-Ti particles (Figure 9f), which were homogeneously distributed in the matrix, as displayed in Figure 9g. The EDS analysis performed on 10 different samples show that the average composition of Ti- was $2.23 \mathrm{wt} \%$ 


\subsubsection{Color Changes with Changing the RBM Time}

The changes in the samples by visual inspection and discoloration were used conducted as a means to confirm the formation of the $\mathrm{MgH}_{2}$ phase. Figure 10 shows an optical image taken for the samples obtained after RBM at different times.

At the early stage (3-6 h) of RBM, where the samples consisted of large powder particles (Figure 7d or Figure 8a), colors remained consistent when compared with the color of the feedstock (Figure 1i). The grayish color changed to darker shades upon RBM for $12.5 \mathrm{~h}$ (Figure 10), indicating the formation of finer powder particles (Figure 7e, and Figure $8 \mathrm{a}$ ). Increasing the RBM time $(18 \mathrm{~h})$ enhanced the mechanically-induced gas-solid reaction, where a considerable volume fractions of $\mathrm{MgH}_{2} \mathrm{phase}$ were obtained, as confirmed by the thermal analysis (Section 3.2.1.) and hydrogenation kinetics measurements (Section 3.3). Accordingly, the color of the sample changed from a dark -grey to light brown (beige), as shown in Figure 10. After $25 \mathrm{~h}$ of RBM, where the volume fraction of $\mathrm{MgH}_{2} \mathrm{was}$ increased against the unreacted Mg-shots (Figure 9a) the color of the sample had a brown color, as shown in Figure 10.

The brown color of the samples was gradually changed into dark brown upon increasing the RBM time 37.5 and $50 \mathrm{~h}$ (Figure 10), implying an increase in volume fraction $\mathrm{MgH}_{2}$ powders and formation of finer particles. The powders obtained after 100-150 h of RBM, which revealed a tetragonal structure corresponding to the $\mathrm{MgH}_{2}$ phase (Figure 9b) had a dark brown color, as displayed in Figure 10. The changes from light -brown to dark -brown color can be used as a rough indication of formation fine nanopowder nanoparticles (Figure 1e, Figure 7i, or Figure 8a).

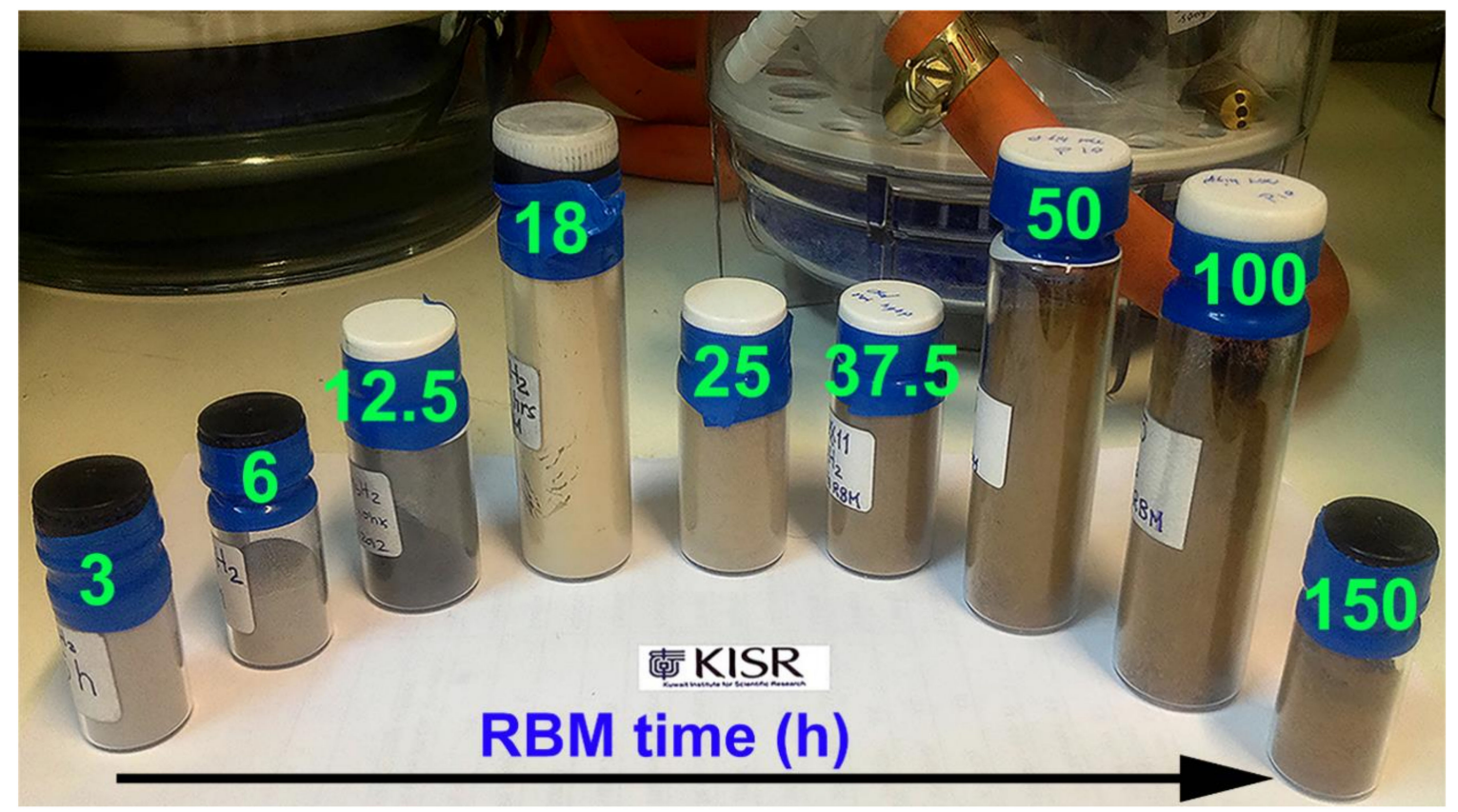

Figure 10. As—cold rolled Mg—shots milled for different RBM time (3, 6, 12.5, 18, 25, 37.5, 50, 100, and 150 h). The significant effect of RBM time on the samples' color is notified.

\subsection{Thermal Analysis}

\subsubsection{Differential Scanning Calorimetry Measurements}

The thermal stability of all samples, characterized by the decomposition temperature $\left(\mathrm{T}^{\mathrm{dec}}\right)$ of $\mathrm{MgH}_{2}$ powders were investigated with DSC using a heating rate of $10^{\circ} \mathrm{C} / \mathrm{min}$ and a He gas flow of $50 \mathrm{~mL} / \mathrm{min}$. Figure 11a shows the DSC thermograms of Mg-strips that CR for 0, 25, 50, 75, and 150 passes before being hydrogenated at $300^{\circ} \mathrm{C}$. Meanwhile, the DSC traces for the as-CR Mg strips 
for 150 passes and then subjected to RBM under $\mathrm{H}_{2}$ gas pressure for $3,12.5,25,50$, and $100 \mathrm{~h}$ and are shown collectively in Figure 11b.

All the $\mathrm{MgH}_{2}$ strips without exception revealed single endothermic events related to the decomposition of the $\mathrm{MgH}_{2}$ phase. The position of the endothermic peaks tended to shift upon increasing the $\mathrm{CR}$ passes, as suggested by the decrease in $\mathrm{T}^{\text {dec }}$ value of the $\mathrm{MgH}_{2}$ phase (Figure 11a). The starting MS -Mg ribbons (0 passes) displayed a high value of $\mathrm{T}^{\mathrm{dec}}\left(404^{\circ} \mathrm{C}\right)$, increasing CR passes to 50 and 75 , which led to an outstanding decrease of $\mathrm{T}^{\mathrm{dec}}$ to $377^{\circ} \mathrm{C}$ and $362^{\circ} \mathrm{C}$, respectively (Figure 11a). Towards the end of $\mathrm{CR}$ processing (150 passes), the $\mathrm{H}_{2}$ was released at a relatively low $\mathrm{T}^{\text {dec }}$ of $354^{\circ} \mathrm{C}$.

Elsewhere, the decomposition behavior of as-CR Mg-ribbons for 150 passes and then RBM for different RBM time, showed superior improvement with increasing the RBM time (Figure 11b). The $\mathrm{T}^{\text {dec }}$ of the sample milled for $12.5 \mathrm{~h}\left(379^{\circ} \mathrm{C}\right)$ decreased to $374{ }^{\circ} \mathrm{C}$ and $364{ }^{\circ} \mathrm{C}$ after $25 \mathrm{~h}$ and 50 , respectively (Figure 11b). Further improvement in $\mathrm{T}^{\mathrm{dec}}$ was attained with increasing the RBM time to $75 \mathrm{~h}\left(351^{\circ} \mathrm{C}\right)$ and $100 \mathrm{~h}\left(337^{\circ} \mathrm{C}\right)$, as shown in Figure $11 \mathrm{~b}$.

It can be concluded that the mechanical treatment of Mg-ribbons, using two consequent steps of $\mathrm{CR}$ and RBM techniques led to a superior improving of the decomposition characteristics of $\mathrm{MgH}_{2}$. We should emphases that when $\mathrm{MgH}_{2}$ powder was prepared upon $\mathrm{RBM}$ of $\mathrm{Mg}$ under pressurized $\mathrm{H}_{2}$ gas, the recorded value of $\mathrm{T}^{\mathrm{dec}}$ was $399^{\circ} \mathrm{C}$ [48]. Comparing that value with the one investigated in the present study $\left(337^{\circ} \mathrm{C}\right)$, we can claim that the $\mathrm{CR}$ process is an important primary step that should be employed prior to the RBM process. In addition to the importance of $\mathrm{CR}$ treatment, the degradation presented in the $\mathrm{T}^{\mathrm{dec}}$ for $\mathrm{MgH}_{2}$ powders, could be partially attributed to the presence of significant molecular fractions $(2.23 \mathrm{wt} \%$ ) of Ti fine particles that were worn out from Ti-balls milling media and gradually introduced into the $\mathrm{MgH}_{2}$ matrix during the $\mathrm{RBM}$ process. It is worth noting that when the conventional tool-steel balls were used as milling media, the $\mathrm{T}^{\mathrm{dec}}$ value of as- $\mathrm{RBM} \mathrm{MgH}_{2}$ powders was $402{ }^{\circ} \mathrm{C}[49]$.
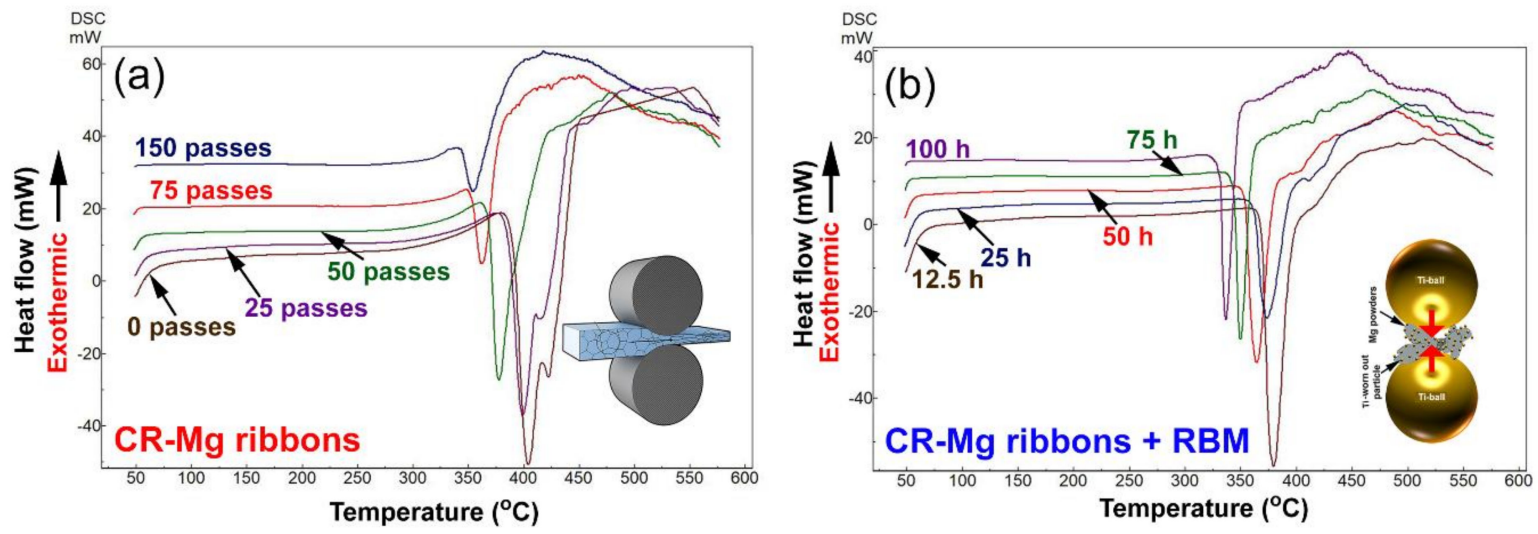

Figure 11. Differential scanning calorimeter (DSC) thermograms of Mg-ribbons (a) obtained after CR for different passes $\left(0,25,50,75\right.$, and 150 passes), and then hydrogenated at $300{ }^{\circ} \mathrm{C}$, and (b) obtained after CR for 150 passes, and then RBM under hydrogen gas pressure for 12.5, 25, 50, 75, and $100 \mathrm{~h}$ of RBM time.

\subsubsection{Correlations between Processing Approaches, Grain Size and Decomposition Temperatures}

The influence of processing approaches ( $\mathrm{CR}$ and $\mathrm{CR}+\mathrm{RBM}$ ), on the grain size, and $\mathrm{T}^{\mathrm{dec}}$ for $\mathrm{MgH}_{2}$ has been investigated as a function of the processing time (CR passes and $\mathrm{RBM}$ time). The grain sizes of all samples were measured by the FE-HRTEM technique. The grain size of $\mathrm{MgH}_{2}$ prepared from the as-cast $\mathrm{Mg}$ ingot (0 passes) was $531 \mathrm{~nm}$, where its corresponding $\mathrm{T}^{\mathrm{dec}}$ was $404^{\circ} \mathrm{C}$, as shown in Figure 12a. When the sample was CR for 25 and 50 passes, their grains decreased significantly to $452 \mathrm{~nm}$ and $380 \mathrm{~nm}$, respectively (Figure 12a). Accordingly, the corresponded $\mathrm{T}^{\mathrm{dec}}$ for 25 passes and 50 passes samples were significantly decreased to reach $399^{\circ} \mathrm{C}$ and $377^{\circ} \mathrm{C}$, respectively. The introduction of high-density imperfections (Figure 5a) through further CR passes (75 to 150 passes) 
disintegrated the $\mathrm{Mg}$ particles into finer nanosized grains, ranging between $296 \mathrm{~nm}$ to $145 \mathrm{~nm}$, as shown in Figure 12a. The presence of these fine $\mathrm{MgH}_{2}$ minimized the $\mathrm{H}_{2}$ diffusion distance, leading to recorded $\mathrm{T}^{\text {dec }}$ for 75 passes and 150 passes samples were $362^{\circ} \mathrm{C}$ and $354^{\circ} \mathrm{C}$, respectively (Figure 12a).

The mechanically deformed Mg-ribbons obtained after 150 passes were subjected to different types of imperfections upon through RBM process. In this process, the materials were subjected to point and lattice defects, as well as severe dislocations [33-49], led to a dramatic reduction of the grain size. The results showed that both the grain size and $\mathrm{T}^{\mathrm{dec}}$ were linearly decreased parallel to each other upon increasing the RBM time (Figure 12b). After $12.5 \mathrm{~h}$ of $\mathrm{RBM}$ time, the grain size of $\mathrm{MgH}_{2}$ powders was significantly reduced $(145 \mathrm{~nm})$, where the corresponding $\mathrm{T}^{\mathrm{dec}}$ was measured to be $379^{\circ} \mathrm{C}$, as presented in Figure $12 \mathrm{~b}$.

Increasing the RBM time ( $25 \mathrm{~h}$ to $50 \mathrm{~h}$ ) led to a drastic decrease in the gain size of $\mathrm{MgH}_{2}(112 \mathrm{~nm}$ to $73 \mathrm{~nm}$ ). This rapid decrease in the grain size improved the dehydrogenation process, as indicated by the rapid decrease in their $\mathrm{T}^{\mathrm{dec}}$ reaching $374^{\circ} \mathrm{C}$ and $364^{\circ} \mathrm{C}$, respectively (Figure 12b). Towards the end of RBM process ( $75 \mathrm{~h}$ to $100 \mathrm{~h}$ ) the samples grain sizes were severely reduced to $18 \mathrm{~nm}$ and $7 \mathrm{~nm}$ in diameter (Figure 1e or Figure 9c), where their $\mathrm{T}^{\mathrm{dec}}$ values reached to $351{ }^{\circ} \mathrm{C}$ and $337^{\circ} \mathrm{C}$, respectively (Figure 12b).
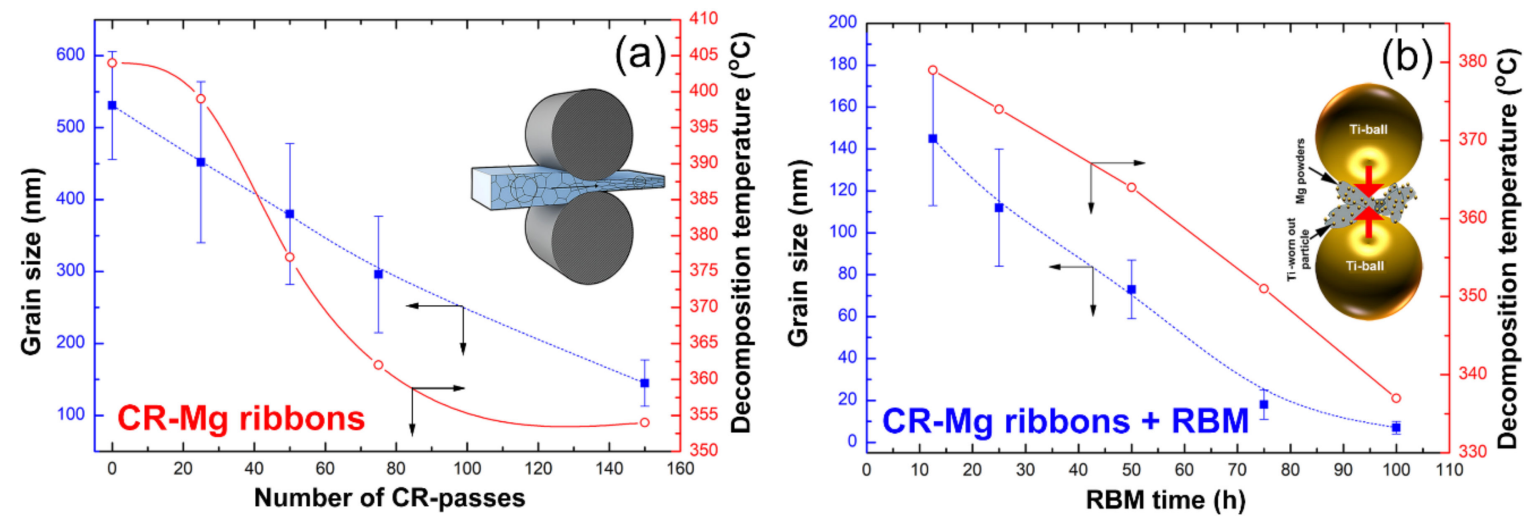

Figure 12. Correlations between processing approaches, grain sizes, and decomposition temperature for $\mathrm{MgH}_{2}$ prepared through (a) $\mathrm{CR}$, and (b) $\mathrm{CR}+\mathrm{RBM}$ techniques.

\subsection{Hydrogenation/Dehydrogenation Kinetics}

The effect of processing on the hydrogenation and dehydrogenation kinetics behavior of all samples was investigated as a function of processing time (CR-passes and RBM time). In these experiments, the samples were first activated at $350{ }^{\circ} \mathrm{C}$ under high $\mathrm{H}_{2}$ pressure of $35 \mathrm{bar}$ for $4 \mathrm{~h}$. The samples were then subjected to 100 continuous sorption/desorption cycles, conducted at $300{ }^{\circ} \mathrm{C}$ under $\mathrm{H}_{2}$ gas pressure fluctuated from 35 bar (absorption) to 400 mbar (desorption). The activation process is a necessary step to reduce the thin $\mathrm{MgO}$ layer coated the powder, which prevents the hydrogen gas to react with the fresh surfaces of $\mathrm{Mg}$ metals. In all experiments, the hydrogenation reactions were conducted at $275^{\circ} \mathrm{C}$ under 10 bar of $\mathrm{H}_{2}$ gas pressure. However, the dehydrogenation kinetics were investigated at $275^{\circ} \mathrm{C}$ under $400 \mathrm{mbar}$ of hydrogen gas pressure.

\subsubsection{CR-Mg Ribbons}

Figure 13 displays the effect of RBM time on the hydrogenation (a) and dehydrogenation kinetics of as-CR Mg ribbons for different passes, ranging from 75 to 150 passes. All the CR samples revealed a good ability to absorb hydrogen at different time scales, as shown in Figure 13a. The samples that were subjected to $\mathrm{CR}$ of 75 and 100 passes, revealed slow kinetics, characterized by a low hydrogen concentration (2.6-2.7 wt\%) absorbed after $5 \mathrm{~min}$ (Figure 13a). In contrast, the CR sample for 150 passes, was capable to absorb $3.3 \mathrm{wt} \% \mathrm{H}_{2}$ after $5 \mathrm{~min}$, as presented in Figure 13a. Increasing the applied absorption time to $12.5 \mathrm{~min}$ led to a remarkable increase in the hydrogen absorbed by the samples $\mathrm{CR}$ 
for 75 passes (3.3 $w t \%)$ and 100 passes (305 wt\%), as displayed in Figure 13a. After this absorption time, the sample CR for 150 passes showed better hydrogenation kinetics, indicated by its highest hydrogen concentration value of $4 \mathrm{wt} \%$, as shown in Figure 13a. Both of the samples, which were CR for 75 passes and 100 passes, required saturation for $42 \mathrm{~min}$ and $31 \mathrm{~min}$ to get saturation values of almost $4 \mathrm{wt} \% \mathrm{H}_{2}$ (Figure 13a).
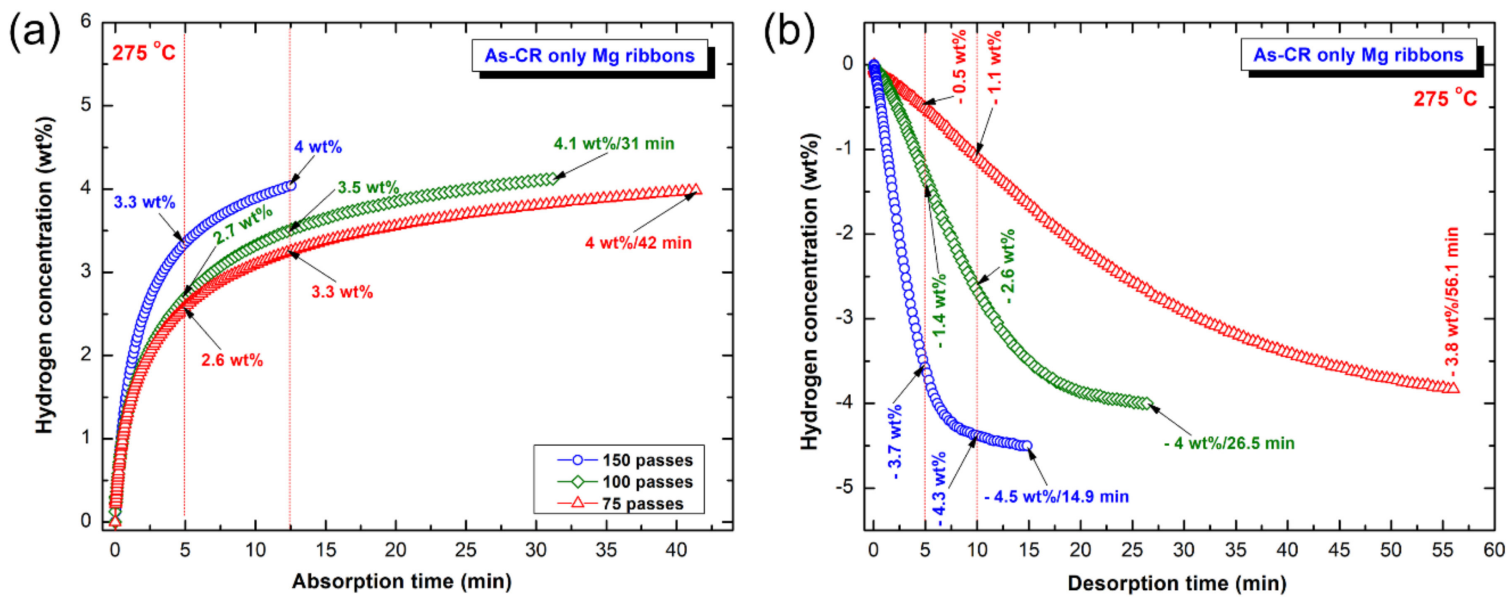

Figure 13. The kinetics of (a) hydrogenation, and (b) dehydrogenation measured at $275{ }^{\circ} \mathrm{C}$ for $\mathrm{CR}$ Mg-ribbons obtained after 75, 100 and 150 passes. The hydrogenation and consequent dehydrogenation processes were conducted under 10 bar and 400 mbar of $\mathrm{H}_{2}$ pressure, respectively.

Likewise, the hydrogenation kinetics that was improved with increasing the number of $\mathrm{CR}$ passes applied to Mg-ribbons, the dehydrogenation kinetics of $\mathrm{MgH}_{2}$ behaved in the same manner. The CR samples for 75 and 100 passes revealed slow kinetics of hydrogen desorption, as suggested by their very low hydrogen concentration of $-0.5 \mathrm{wt} \%$ and $-1.4 \mathrm{wt} \%$ obtained after $5 \mathrm{~min}$, respectively (Figure 13b). Their dehydrogenation kinetics were marginally improved upon increasing the applied desorption time (10 $\mathrm{min}$ ), as suggested by increasing hydrogen concentration to $-1.1 \mathrm{wt} \%$ and $-2.6 \mathrm{wt} \%$, respectively (Figure 13b). After very long desorption time (56.1 $\mathrm{min}$ ) the hydrogen concentration of the sample CR for 75 passes reached $-3.8 \mathrm{wt} \%$, as displayed in Figure 13b. The CR sample for 100 passes showed better desorption kinetics, implied by the rather shorter time ( $26.5 \mathrm{~min}$ ) required to desorb $-4 \mathrm{wt} \% \mathrm{H}_{2}$, as presented in Figure 13b. Superior Improvement in the dehydrogenation kinetics was attained upon $\mathrm{CR}$ the sample for 150 passes. This was implied by the sample capability to release -3.7 and $4.3 \mathrm{wt} \%$ $\mathrm{H}_{2}$ within 5 and $10 \mathrm{~min}$, respectively (Figure 13b). The sample tended to desorb $-4.5 \mathrm{wt} \% \mathrm{H}_{2}$ after -14.9 min (Figure 13b).

It can be then concluded that increasing the number of $C R$ passes lead to a significant increase in the hydrogen storage capacity of $\mathrm{Mg}$ ribbons and enhanced their hydrogenation/dehydrogenation kinetics. The beneficial effect of CR on the hydrogen storage capacity and the kinetics behavior upon increasing the number of passes can be attributed to the dramatic reduction of crystallite size upon increasing the number of passes, as shown in Figure 12a. Furthermore, the presence of defects in Mg-ribbons upon severe plastic deformation conducted by CR that act as nucleation points for $\mathrm{MgH}_{2}$ is believed to improve the kinetics behavior of the metal hydride phase [50]. Unfortunately, increasing the $\mathrm{CR}$ passes of $\mathrm{Mg}$-ribbons may lead to the formation of $\mathrm{MgO}$ layer coating the $\mathrm{Mg}$-ribbon, as pointed out by Hout and Tousignant [50].

Figure 14a shows the XRD pattern of as-CR sample for 150 passes and then hydrogenated at $275^{\circ} \mathrm{C} / 10$ bar $\mathrm{H}_{2}$. The sample revealed a tetragonal-structure related to the formation of the $\beta-\mathrm{MgH}_{2}$ phase, as denoted by the red symbols shown in Figure 14a. The very small molar fraction of unreacted hcp- Mg shots exist in the sample (Figure 14a). This may be due to the short- hydrogenation time (12.5 min), applied for this sample (Figure 13a). The XRD pattern of the same sample obtained after dehydrogenation at $275^{\circ} \mathrm{C} / 400 \mathrm{mbar}_{2}$, is presented in Figure $14 \mathrm{~b}$. Those Bragg-peaks related to 
$\beta-\mathrm{MgH}_{2}$ phase (Figure 13a) were replaced by a set of polycrystalline hcp-Mg, as shown in Figure 14b. This implies the completion of the dehydrogenation process, where $\mathrm{H}_{2}$ gas was released from the sample. It should be noted that a very small mole fraction of undecomposed $\beta-\mathrm{MgH}_{2}$ is existed in the sample, as characterized by the low-intensity Bragg-peaks of $\beta-\mathrm{MgH}_{2}$ (Figure $14 \mathrm{~b}$ ). The presence of this undecomposed hydride phase may be attributed to the shortage of the desorption time applied for this sample (14.9 min).

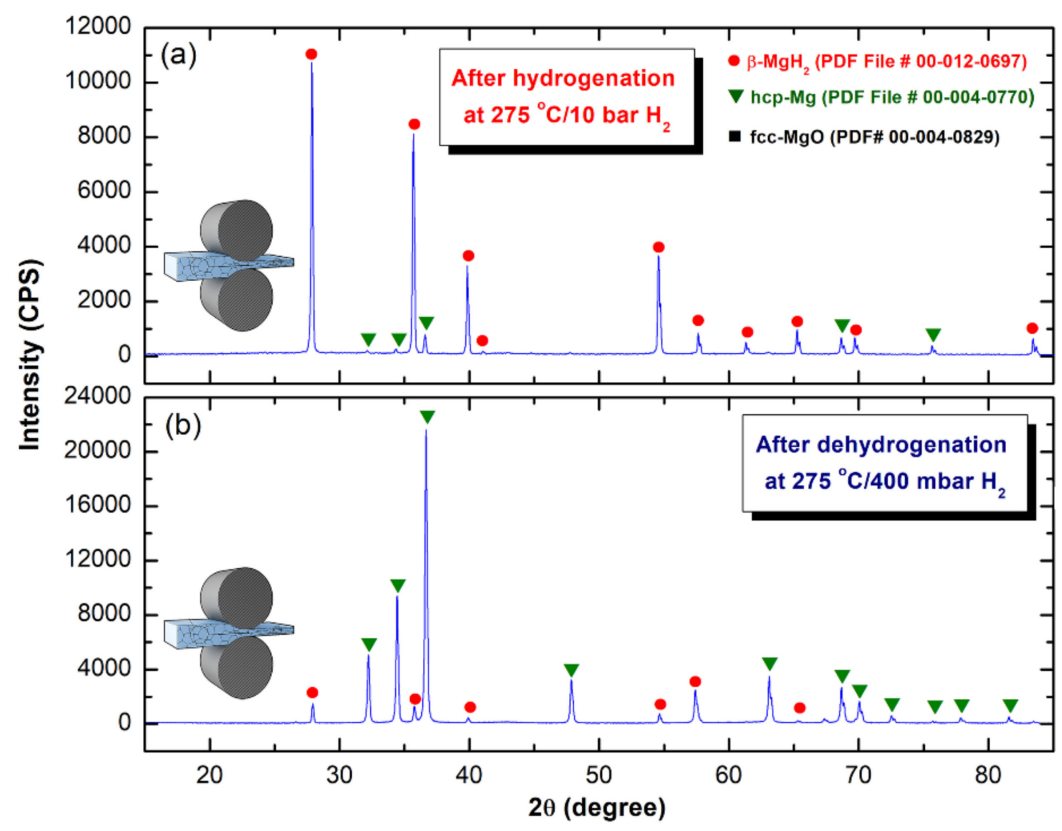

Figure 14. The XRD patterns of the 150 passes-sample obtained after (a) hydrogenation at $275{ }^{\circ} \mathrm{C} /$ 10 bar $\mathrm{H}_{2}$, and (b) dehydrogenation at $275^{\circ} \mathrm{C} / 400 \mathrm{mbar} \mathrm{H}_{2}$.

\subsubsection{RBM Mg Powders}

Despite the improvement in the $\mathrm{H}_{2}$ gas uptake/release kinetics achieved upon CR of Mg-ribbon, the obtained $\mathrm{H}_{2}$ storage capacity is modest, when compared with the theoretical hydrogen capacity of $\mathrm{MgH}_{2}$ [45]. In addition, the hydrogenation/dehydrogenation kinetics needs further improvement. These drawbacks of $\mathrm{CR}$ are mainly attributed to the disability of the process to produce nano-dimensional crystallites (under $100 \mathrm{~nm}$ ) of $\mathrm{MgH}_{2}$ powders as presented in Figure 12a. Preparing $\mathrm{MgH}_{2}$ powders starting from pure $\mathrm{Mg}$ metal powders through the RBM technique is considered to be powerful tool to obtain nanocrystalline grains with sizes ranging between $8 \mathrm{~nm}$ to $15 \mathrm{~nm}$ in diameter [48,49].

In contrast to the beneficial size-reduction attained by RBM, the hydrogenation/dehydrogenation kinetics of the corresponding powders are rather poor $[21,23,30,39]$ and required to be severely improved. One approach used to improve the kinetics behavior of $\mathrm{RBM}$ powders catalyzed the $\mathrm{MgH}_{2}$ with one or more catalytic agents, as discussed in the introduction. However, doping the hydride phase with catalysts leads to enhancing its kinetics behavior, it leads to a significant degradation in the hydrogen storage capacity of $\mathrm{MgH}_{2}$ [20]. Moreover, the $\mathrm{RBM}$ technique does not introduce a high density of plastic deformation to the milled powders, when compared with the CR process $[41,50]$. Here, we have tried to combine the beneficial effects of the three methods (e.g., CR, RBM, and catalyzation) together in one approach. For this purpose, the CR Mg-ribbons for 150 passes were used as feedstock materials for RBM, conducted under 15 bar of $\mathrm{H}_{2}$ gas pressure. Instead of using the common tool-steel balls, Ti-balls were employed as milling media. The purpose of using Ti-balls is to conduct in-situ catalyzation of $\mathrm{MgH}_{2}$ with Ti fine particles that worn from the balls during the milling process.

The hydrogenation/dehydrogenation kinetics behavior of CR Mg-ribbons investigated after 25, 50, and $100 \mathrm{~h}$ of RBM is shown in Figure $15 \mathrm{a}, \mathrm{b}$, respectively. At the early stage of RBM (25 h), the powders 
revealed slow hydrogenation kinetics at $275^{\circ} \mathrm{C}$, as characterized by the rather long time of $300 \mathrm{~s}(5 \mathrm{~min})$ required to absorb $5.43 \mathrm{wt} \% \mathrm{H}_{2}$ ), as presented in Figure 15a. Increasing the absorption time to $500 \mathrm{~s}$ ( $~ 8.3 \mathrm{~min})$ and $1000 \mathrm{~s}(\sim 16.7 \mathrm{~min})$ led to a remarkable increase in the hydrogen storage capacity that reached to 5.87 and $6.2 \mathrm{wt} . \% \mathrm{H}_{2}$, respectively (Figure 15a). The slow gas uptake kinetics was attributed to the morphological characteristics of the sample obtained after $25 \mathrm{~h}$ of RBM, which composited of large crystallites, and a small molecular fraction of Ti, as schematically presented in Figure 16.
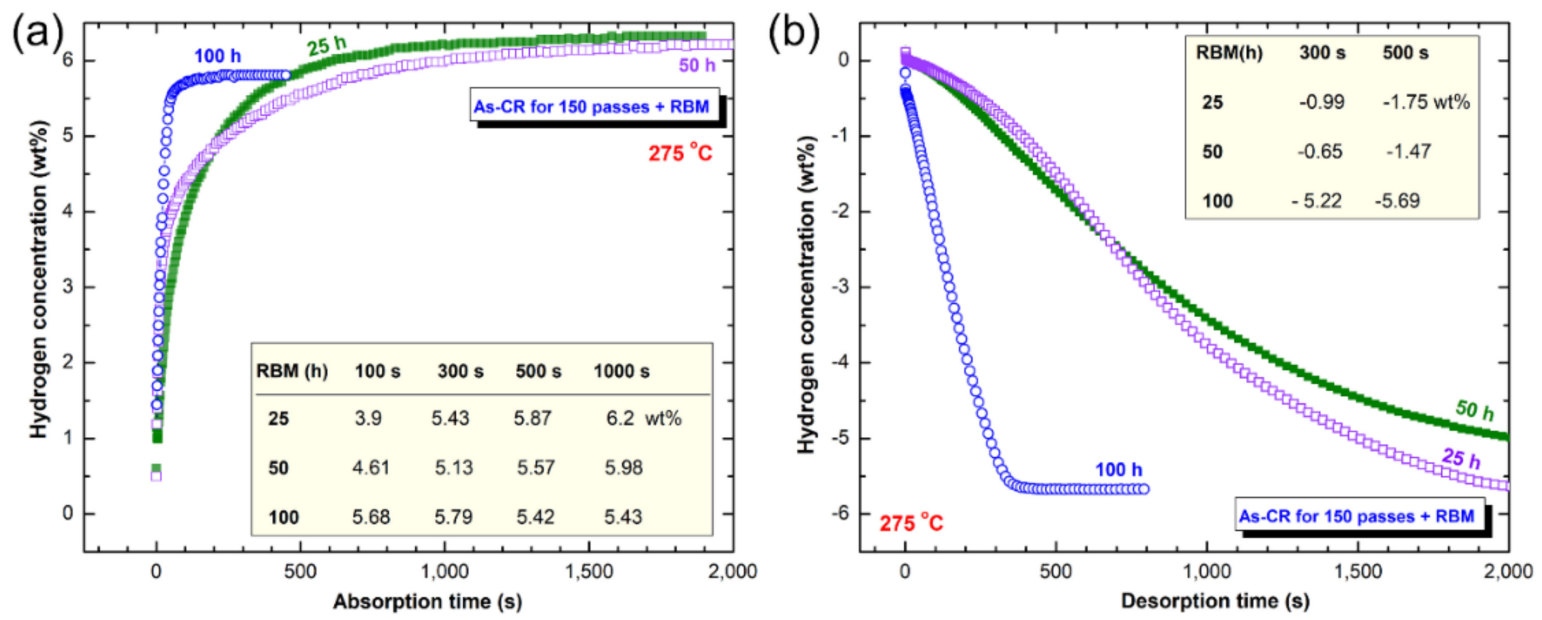

Figure 15. The kinetics of (a) hydrogenation, and (b) dehydrogenation measured at $275{ }^{\circ} \mathrm{C}$ for $\mathrm{CR}$ Mg-ribbons obtained after 150 passes, and then RBM for 25, 50, and $100 \mathrm{~h}$. The hydrogenation and consequent dehydrogenation processes were conducted under 10 bar and $400 \mathrm{mbar}$ of $\mathrm{H}_{2}$ pressure, respectively.

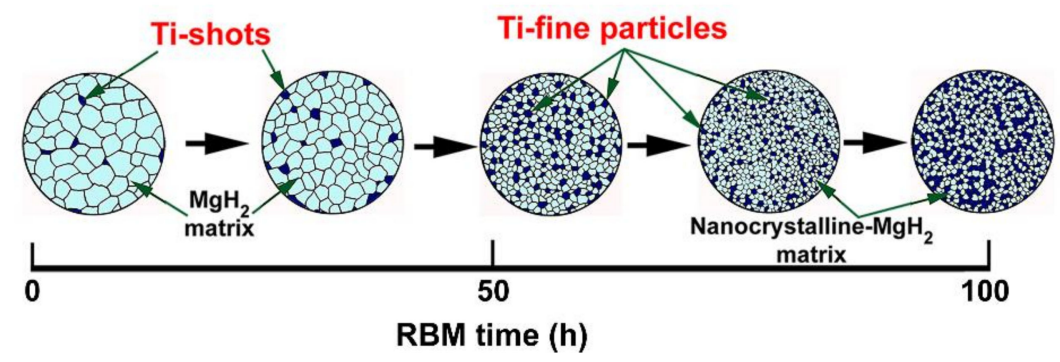

Figure 16. A Schematic presents the effect of $\mathrm{RBM}$ time in the reduction of $\mathrm{MgH}_{2}$ grain sizes. During the RBM process, Ti particles were worn out from the Ti-balls and gradually embedded into the $\mathrm{MgH}_{2}$ matrix. These spheroid particles that acted as nanocatalytic agent led to improve the hydrogenation/dehydrogenation kinetics of $\mathrm{MgH}_{2}$ nanopowders.

The hydrogenation kinetics behavior of the 50 h-RBM sample was very close to the sample obtained after $25 \mathrm{~h}$ of RBM. This is indicated by the close values of hydrogen storage and the absorption time required to get saturation, as shown in table inset of Figure 15a. It should be noted that the $\mathrm{H}_{2}$ storage capacity of the sample obtained after $50 \mathrm{~h}(5.98 \mathrm{wt} \%)$ is less than the one showed for $25 \mathrm{~h}$ (Figure 15a). This was attributed to the higher volume fraction of $\mathrm{Ti}(\sim 1.42 \mathrm{wt} \%)$ introduced to the sample.

Increasing the RBM time $(100 \mathrm{~h})$ led to a decrease in the size for both of the $\mathrm{MgH}_{2}$ crystallites and Ti particles (Figure 16) upon introducing a high-density imperfection network in milled powder. As the crystallite size of the metal hydride decreased, the hydrogen diffusion distance was also decreased to facilitate faster kinetics [30]. This coupled with an increase in the molecular fraction of Ti-particles $\left(2.23 \mathrm{wt} \%\right.$ ) worn out from the balls and embedded into the $\mathrm{MgH}_{2}$ matrix, as shown in Figure 16. The $100 \mathrm{~h}$-RBM sample possessed superior absorption kinetics, indexed by a very short time of $100 \mathrm{~s}$ ( $1.7 \mathrm{~min})$ needed to absorb $-5.68 \mathrm{wt} \% \mathrm{H}_{2}$, as shown in Figure 15a. After $300 \mathrm{~s}$ (5 min), the sample 
was almost saturated at $5.79 \mathrm{wt} \% \mathrm{H}_{2}$ (Figure 15a). The dehydrogenation kinetics of as-CR Mg-ribbons for 150 passes that were RBM for different time $(25,50$, and $100 \mathrm{~h})$ are presented in Figure $15 \mathrm{~b}$. Those samples obtained after 25 and $50 \mathrm{~h}$ of RBM possessed poor desorption kinetics, characterized by a long time of $2000 \mathrm{~s}$ ( $\sim 33.3 \mathrm{~min})$ necessary to release -1.75 and $-1.47 \mathrm{wt} \% \mathrm{H}_{2}$, respectively (Figure $\left.15 \mathrm{~b}\right)$. In contrast, the sample, which was obtained after longer RBM time (100 h) revealed superior desorption behavior, characterized by a short time of $500 \mathrm{~s}(\sim 8.3 \mathrm{~min})$ consumed to release $5.69 \mathrm{wt} \% \mathrm{H}_{2}$, as displayed in Figure 15b.

Figure 17 a shows the XRD pattern of the hydrogenated $\left(275^{\circ} \mathrm{C} / 10\right.$ bar $\left.\mathrm{H}_{2}\right) 150$-passes CR sample that was RBM for $100 \mathrm{~h}$. The sample possessed a crystal structure of the tetragonal-structure of $\beta-\mathrm{MgH}_{2}$, as denoted by the red symbols shown in Figure 17a. However, the hydrogenation time applied for this sample was $400 \mathrm{~s}$ (Figure 15a), a very small volume fraction of unreacted Mg powders still existed in the sample obtained after the hydrogenation process. This was suggested by those Bragg lines related to hcp-Mg crystals displayed in Figure 17a. Probably, some of pure Mg powders were adhered to the internal wall of the $\mathrm{Cu}$-sample holder that came out with the hydrogenated powders upon discharging the powder. Meanwhile, the XRD pattern of the same sample obtained after dehydrogenation at $275^{\circ} \mathrm{C} / 400 \mathrm{mbar}_{2}$, is presented in Figure $17 \mathrm{~b}$. The Bragg-peaks related to $\beta-\mathrm{MgH}_{2}$ phase (Figure 17a) were replaced by a set of polycrystalline hcp- $\mathrm{Mg}$, as shown in Figure $17 \mathrm{~b}$. This implying the completion of the dehydrogenation process, and formation of $\mathrm{Mg}$ powders that were coexisted with a very small volume fraction of undecomposed $\beta-\mathrm{MgH}_{2}$ phase, as shown in Figure $17 \mathrm{~b}$.

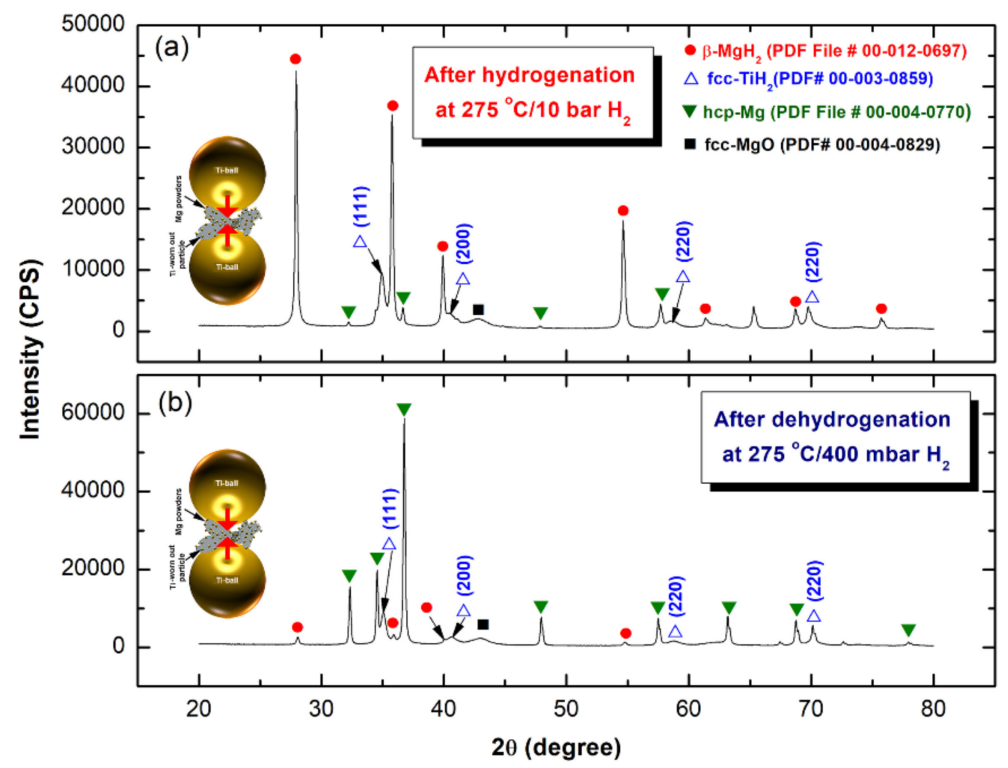

Figure 17. The $\mathrm{XRD}$ patterns of the 150 passes $\mathrm{CR}$ Mg-ribbons that were $\mathrm{RBM}$ for $100 \mathrm{~h}$ and then (a) hydrogenated at $275^{\circ} \mathrm{C} / 10$ bar $\mathrm{H}_{2}$, and (b) dehydrogenated at $275{ }^{\circ} \mathrm{C} / 400 \mathrm{mbar}_{2}$.

\subsubsection{Cycle Lifetime Test}

The capability of nanocomposite the powders obtained after $150 \mathrm{~h}$ of RBM to achieve continuous cyclic hydrogenation/dehydrogenation processes was investigated at $225{ }^{\circ} \mathrm{C}$. This test is necessary to realize the ability of the fabricated nanocomposite system on maintaining their hydrogen storage capacity and fast hydrogenation/dehydrogenation kinetic without serious degradation or failure. In the present study, a small amount $(\sim 350 \mathrm{mg})$ of the powders was continuously subjected to hydrogenation/dehydrogenation cycles conducted at $275^{\circ} \mathrm{C}$ under a hydrogen gas pressure of 10 bar (hydrogenation) $400 \mathrm{mbar}$ (dehydrogenation) for $200 \mathrm{~h}$. In this experiment, the powders were firstly activated with applying cyclic hydrogen gas sorption/desorption under a pressure of 35 bar at $350{ }^{\circ} \mathrm{C}$ for $30 \mathrm{~h}$. This treatment was necessary for the surface cleaning of the powders and to break down 
the oxide film $(\mathrm{MgO})$ developed on the powder surfaces during handling the sample outside of the glove box.

Figure 18a shows the hydrogen absorbed/desorbed cycles achieved continuously for $200 \mathrm{~h}$ at a temperature of $275^{\circ} \mathrm{C}$. This system possessed an excellent hydrogenation/dehydrogenation cyclability, demonstrated by achieving continuous 320 cycles within $200 \mathrm{~h}$ without failure (Figure 18a). No serious degradation in the hydrogen storage capacity, which was in the range between $5.73-5.85 \mathrm{wt} \%$, could be detected even after $200 \mathrm{~h}$, as shown in Figure 18a. Moreover, the kinetics of the hydrogenation/dehydrogenation processes remaining nearly constant without failure or serious decay. It can be noticed that doping $\mathrm{MgH}_{2}$ with Ti nanoparticles that worn for the Ti-balls during RBM allowed the catalytic agent particles to occupy the surface of $\mathrm{MgH}_{2}$ powders with uniform distribution, as shown in Figure 18a. During the hydrogenation process, all the Ti nanoparticles reacted with $\mathrm{H}_{2}$ gas at $275{ }^{\circ} \mathrm{C} / 10$ bar $\mathrm{H}_{2}$ to form $\mathrm{TiH}_{2}$ nanopowders that were uniformly distributed in the $\mathrm{MgH}_{2}$ matrix, as shown in Figure 18b.
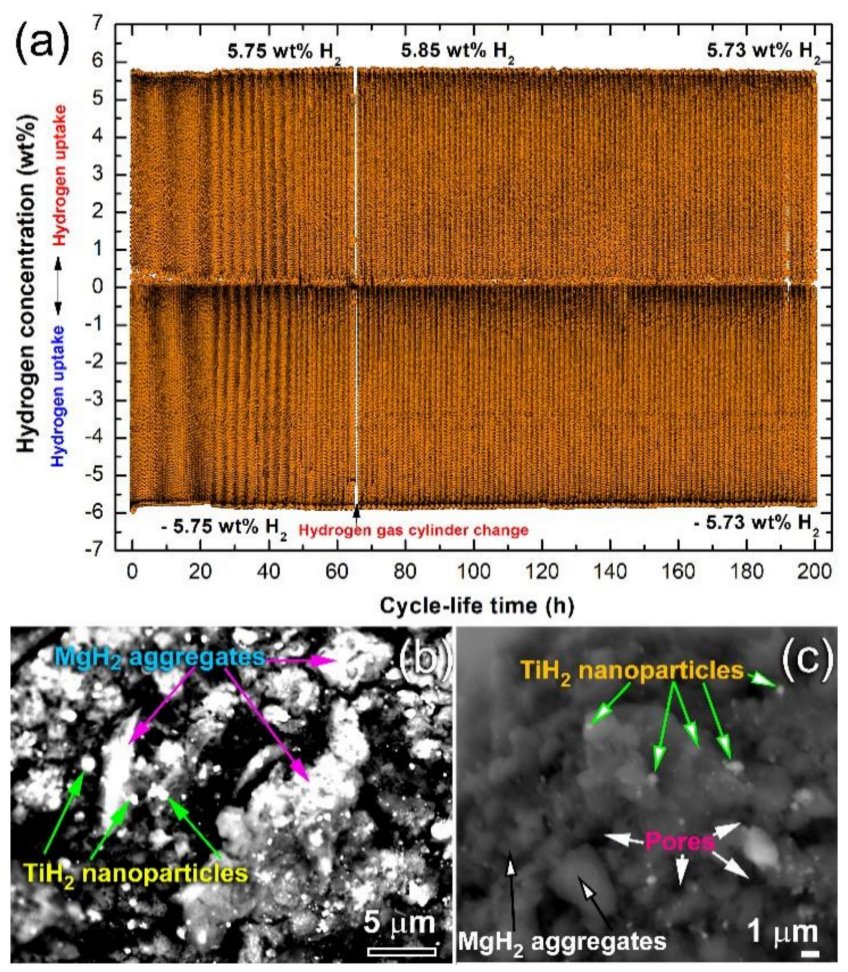

Figure 18. (a) Cycle-life-time curves of the 150 passes -CR sample, which was RBM for $150 \mathrm{~h}$. The FE-backscattered electrons (BSE) micrographs of the samples taken after $199.5 \mathrm{~h}$ hydrogenation and $200 \mathrm{~h}$ dehydrogenation time are presented in (b), and (c), respectively. The $\mathrm{H}_{2}$-uptake and release were conducted at $275^{\circ} \mathrm{C} / 10$ bar $\mathrm{H}_{2}$, and $275^{\circ} \mathrm{C} / 400 \mathrm{mbar} \mathrm{H}_{2}$, respectively.

\section{Conclusions}

Utilization of solid waste (SW) Mg metal for tailoring high-hydrogen storage capacity nanoparticles has never been reported as yet. The present study demonstrated an effective multistage process used to fabricate high-grade of $\mathrm{Mg}$ metal, stating from $\mathrm{Mg}$ machining chips. Melting/casting, melt spinning (MS), cold rolling (CR) were dedicated to producing purity $\mathrm{Mg}$ strips $(99.88 \mathrm{wt} \%)$. The recycled Mg-metal was used as feedstock materials for synthesizing nanocrystalline $\mathrm{MgH}_{2}$ powders through a reactive ball milling (RBM) approach, using a tumbler ball mill pressurized with 15 bar of $\mathrm{H}_{2}$ gas. The following main conclusions could be drawn from this investigation:

- MS technique is an ideal technique used to produce thin Mg-ribbons. 
- CR process is a vital step used to introduce severe plastic deformation in Mg-ribbons, resulting in the formation of fine crystallites.

- Increasing the number of CR passes led to a significant reduction in the Mg crystallites. Accordingly, this led to an increase in the hydrogen storage capacity of metallic $\mathrm{Mg}$ and enhance the hydrogenation/dehydrogenation kinetics.

- Further increase in the hydrogen storage capacity and superior improvement in the gas uptake/release kinetics can be attained upon ball milling the as-CR Mg ribbons under high $\mathrm{H}_{2}$ pressure.

- Using Ti-balls milling media had obvious benefits for improving the hydrogenation/dehydrogenation processes that were taken place very fast when compared with $\mathrm{MgH}_{2}$ powders milled with tool steel-balls.

Author Contributions: M.S.E.-E., and S.M.A.-S. Experimental design, intial draft preparation and review. N.A. reviews the written article. M.S.E.-E., sample preparation with N.A. The TEM, SEM and hydrogenation/dehydrogenation experiments were conducted by M.S.E.-E., where N.A. conducted the XRD and DSC measurements. All authors have read and agreed to the published version of the manuscript.

Funding: This work has been partially funded by the Kuwait Foundation for the Advancement of Sciences (KFAS) related to the Project EA078C under a contract number: PR1814SP12.

Acknowledgments: The financial support received by the Kuwait Government through the Kuwait Institute for Scientific Research for purchasing the equipment used in the present work, using the budget dedicated to the project led by the first author (P-KISR-06-04) of Establishing Nanotechnology Center in KISR is highly appreciated.

Conflicts of Interest: The authors declare no conflict of interest. The funder had no role in the design of the study; in the collection, analyses, or interpretation of data; in the writing of the manuscript, or in the decision to publish the results.

\section{References}

1. Al-Salem, S.M.; Lettieri, P.; Baeyens, J. The valorization of plastic solid waste (PSW) by primary to quaternary routes: From re-use to energy and chemicals. Prog. Energy Combust. Sci. 2010, 36, 103-129. [CrossRef]

2. Al-Salem, S.M.; Lettieri, P.; Baeyens, J. Recycling and recovery routes of plastic solid waste (PSW): A review. Waste Manag. 2009, 29, 2625-2643. [CrossRef] [PubMed]

3. Zhao, Z.; Xiao, F. Amirkhanian, Recent applications of waste solid materials in pavement engineering. J. Waste Manag. 2020, 108, 78-105. [CrossRef] [PubMed]

4. Yue, K. Comparative Analysis of scrap car recycling management policies. Procedia Environ. Sci. 2012, 16, 44-50. [CrossRef]

5. Tang, Z.; Li, W.; Tam, V.; Xue, C. Advanced progress in recycling municipal and construction solid wastes for manufacturing sustainable construction materials. Resour. Conserv. Recycl. X 2020. [CrossRef]

6. Cui, F.; Wang, G.; Yu, D.; Gan, X.; Tian, Q.; Guo, X. Towards “zero waste” extraction of nickel from scrap nickel-based superalloy using magnesium. J. Clean. Prod. 2020, 262. [CrossRef]

7. Wu, S.; Ji, Z.; Ming, H.; Hu, M.; Huang, Z.; Tian, C.; Wu, M. Microstructure and mechanical properties of AZ31B magnesium alloy prepared by solid state recycling. Rare Metal Mater. Eng. 2018, 47, 736-741. [CrossRef]

8. Lucci, R.; López Padilla, R.; Cantero, S.; Bariles, R.; Oldani, C. Refining of AZ91 magnesium alloy obtained in machining chips recycling. Procedia Mater. Sci. 2015, 8, 886-893. [CrossRef]

9. Paraskevas, D.; Dadbakhsh, S.; Vleugels, J.; Vanmeensel, K.; Dewulf, W.; Duflou, J. Solid state recycling of pure $\mathrm{Mg}$ and AZ31 Mg machining chips via spark plasma sintering. Mater. Des. 2016, 109, 520-529. [CrossRef]

10. Ali, Y.; Qiu, D.; Jiang, B.; Pan, F.; Zhang, M.-X. Current research progress in grain refinement of cast magnesium alloys: A review article. J. Alloys Compd. 2015, 619, 639-651. [CrossRef]

11. Shao, H.; Xin, G.; Zheng, J.; Li, X.; Akiba, E. Nanotechnology in Mg-based materials for hydrogen storage. Nano Energy 2012, 1, 590-601. [CrossRef]

12. Jain, I.P.; Lal, C.; Jain, A. Hydrogen storage in Mg: A most promising material. Int. J. Hydrog. Energy 2010, 35, 5133-5144. [CrossRef] 
13. El-Eskandarany, M.S. Metallic glassy $\mathrm{Zr}_{70} \mathrm{Ni}_{20} \mathrm{Pd}_{10}$ powders for improving the hydrogenation/ dehydrogenation behavior of $\mathrm{MgH}_{2}$. Nature. Sci. Rep. 2016, 6, 26936. Available online: www.nature.com/scientificreports (accessed on 8 May 2020). [CrossRef] [PubMed]

14. Luo, Q.; Li, J.; Li, B.; Liu, B.; Shao, H.; Li, Q. Kinetics in Mg-based hydrogen storage materials: Enhancement and mechanism. J. Magnes. Alloy. 2019, 7, 58-71. [CrossRef]

15. El-Eskandarany, M.S.; Banyan, M.; Al-Ajmi, F. Environmentally friendly nanocrystalline magnesium hydride decorated with metallic glassy zirconium palladium nanopowders for fuel cell applications. RSC Adv. 2019, 9, 27987. [CrossRef]

16. Colbe, B.; Ares, J.; Barale, J.; Baricco, M.; Buckley, C.; Capurso, G.; Gallandat, N.; Grant, D.M.; Guzik, M.N.; Jacob, I.; et al. Application of hydrides in hydrogen storage and compression: Achievements, outlook and perspectives. Int. J. Hydrog. Energy 2019, 27, 7780. [CrossRef]

17. El-Eskandarany, M.S.; Banyan, M.; Al-Ajmi, F. Cold-rolled magnesium hydride strips decorated with cold-sprayed Ni powders for solid-state hydrogen storage. Int. J. Hydrog. Energy 2019, 44, 16852-16861. [CrossRef]

18. Zhou, C.; Hu, C.; Li, Y.; Zhang, Q. Crystallite growth characteristics of Mg during hydrogen desorption of $\mathrm{MgH}_{2}$. Prog. Nat. Sci. 2020. [CrossRef]

19. Wang, Y.; Wang, Y. Recent advances in additive-enhanced magnesium hydride for hydrogen storage. Prog. Nat. Sci. 2017, 27, 41-49. [CrossRef]

20. El-Eskandarany, M.S. Recent developments in the fabrication, characterization and implementation of $\mathrm{MgH}_{2}$-based solid-hydrogen materials in the Kuwait Institute for Scientific Research. RSC Adv. 2019, 9, 9907-9930. [CrossRef]

21. Sun, Y.; Shen, C.; Lai, Q.; Liu, W.; Wang, D.-W.; Francois, K.; Zinsou, A. Tailoring magnesium based materials for hydrogen storage through synthesis: Current state of the art. Energy Storage Mater. 2018, 10, 168-198. [CrossRef]

22. Hirscher, M.; Yartys, V.; Baricco, M.; Bellosta von Colbed, J.; Blanchard, D.; Bowman, R. Materials for hydrogen-based energy storage-past, recent progress and future outlook. J. Alloys Compd. 2020, 827. [CrossRef]

23. Ouyang, L.; Liu, F.; Wang, H.; Liu, J.; Yang, X.-S.; Sun, L.; Zhu, M. Magnesium-based hydrogen storage compounds: A review. J. Alloys Compd. 2020, 832. [CrossRef]

24. Liang, G.; Huot, J.; Boily, S.; Van Neste, A.; Schulz, R. Catalytic effect of transition metals on hydrogen sorption in nanocrystalline ball milled $\mathrm{MgH}_{2}-\mathrm{Tm}(\mathrm{Tm}=\mathrm{Ti}, \mathrm{V}, \mathrm{Mn}, \mathrm{Fe}$ and $\mathrm{Ni}$ ) systems. J. Alloys Compd. 1999, 292, 247-252. [CrossRef]

25. Chen, J.; Xia, G.; Guo, Z.; Huang, Z.; Liu, H.; Yu, X. Porous Ni Nanofibers with Enhanced Catalytic Effect on the Hydrogen Storage Performance of $\mathrm{MgH}_{2}$. J. Mater. Chem. A 2015, 3, 15843-15848. [CrossRef]

26. Wang, P.; Zhang, H.F.; Ding, B.Z.; Hu, Z.Q. Structural and hydriding properties of composite Mg-ZrFe ${ }_{1.4} \mathrm{Cr}_{0.6}$. Acta Mater. 2001, 49, 921-926. [CrossRef]

27. Yu, X.B.; Yang, Z.X.; Liu, H.K.; Grant, D.M.; Walker, G.S. The effect of a Ti-V-based BCC alloy as a catalyst on the hydrogen storage properties of $\mathrm{MgH}_{2}$. Int. J. Hydrog. Energy 2010, 35, 6338-6344. [CrossRef]

28. Zhou, C.; Fang, Z.Z.; Ren, C.; Li, J.; Lu, J. Effect of Ti intermetallic catalysts on hydrogen storage properties of magnesium hydride. J. Phys. Chem. C 2013, 117, 12973-12980. [CrossRef]

29. El-Eskandarany, M.S.; Al-Matrouk, H.; Shaban, E.; Al-Duweesh, A. Effect of mechanically-induced solid-state doping time on the morphology and hydrogenation cyclability of $\mathrm{MgH}_{2} / 7 \mathrm{Mn}_{3.6} \mathrm{Ti}_{2.4}$ nanocomposite powders. Int. J. Hydrog. Energy 2015, 40, 10139-10149. [CrossRef]

30. El-Eskandarany, M.S.; Shaban, E.; Al-Matrouk, H.; Behbehani, M.; Alkandary, A.; Aldakheel, F.; Ali, N.; Ahmed, S.A. Structure, morphology and hydrogen storage kinetics of nanocomposite $\mathrm{MgH}_{2} / 10 \mathrm{wt} \% \mathrm{ZrNi}_{5}$ powders. Mater. Today Energy 2017, 3, 60-71. [CrossRef]

31. Kumar, S.; Kojima, Y.G.; Dey, K. Morphological effects of $\mathrm{Nb}_{2} \mathrm{O}_{5}$ on $\mathrm{Mg}-\mathrm{MgH}_{2}$ system for thermal energy storage application. Int. J. Hydrog. Energy 2018, 43, 809-816. [CrossRef]

32. El-Eskandarany, M.S.; Al-Nasrallah, E.; Banyan, M.; Al-Ajmi, F. Bulk nanocomposite $\mathrm{MgH}_{2} / 10 \mathrm{wt}^{\mathrm{t}} \mathrm{o}$ $\left(8 \mathrm{Nb}_{2} \mathrm{O}_{5} / 2 \mathrm{Ni}\right)$ solid-hydrogen storage system for fuel cell applications. Int. J. Hydrog. Energy 2018, 43, 23382-23396. [CrossRef] 
33. Polanski, M.; Bystrzycki, J.; Varin, R.; Plocinski, T.; Pisarek, M. The effect of chromium (III) oxide $\left(\mathrm{Cr}_{2} \mathrm{O}_{3}\right)$ nanopowder on the microstructure and cyclic hydrogen storage behavior of magnesium hydride $\left(\mathrm{MgH}_{2}\right)$. J. Alloys Compd. 2011, 509, 2386-2391. [CrossRef]

34. Ma, Z.; Liu, J.; Zhu, Y.; Zhao, Y.; Lin, H.; Zhang, Y.; Li, H.; Zhang, J.; Liu, Y.; Gao, W.; et al. Crystal-facet-dependent catalysis of anatase $\mathrm{TiO}_{2}$ on hydrogen storage of $\mathrm{MgH}_{2}$. J. Alloys Compd. 2020, 822. [CrossRef]

35. Ranjbara, A.; Guoa, Z.P.; Yua, X.B.; Wexler, D.; Calka, A.; Kimd, C.J.; Liu, H.K. Hydrogen storage properties of $\mathrm{MgH}_{2}-\mathrm{SiC}$ composites. Mater. Chem. Phys. 2009, 114, 168-172. [CrossRef]

36. El-Eskandarany, M.S.; Shaban, E.; Alsairafi, A. Synergistic dosing effect of TiC/FeCr nanocatalysts on the hydrogenation/dehydrogenation kinetics of nanocrystalline $\mathrm{MgH}_{2}$ powders. Energy 2016, 104, 158-170. [CrossRef]

37. El-Eskandarany, M.S.; Alkandary, A.; Aldakheel, F.; Al-Saidi, M.; Al-Ajmi, F.; Banyan, M. Performance and fuel cell applications of reacted ball-milled $\mathrm{MgH}_{2} / 5.3 \mathrm{wt} \% \mathrm{TiH}_{2}$ nanocomposite powders. RSC Adv. 2018, 8, 38175-38185. [CrossRef]

38. Song, J.-Z.; Zhao, Z.-Y.; Zhao, X.; Fu, R.-D.; Han, S.-M. Hydrogen storage properties of $\mathrm{MgH}_{2}$ co-catalyzed by $\mathrm{LaH}_{3}$ and $\mathrm{NbH}$. Int. J. Miner. Metall. Mater. 2017, 24, 1183-1191. [CrossRef]

39. Liu, M.; Zhao, S.; Xiao, X.; Chen, M.; Sun, M.; Yao, Z.; Hu, Z.; Chen, L. Novel 1D carbon nanotubes uniformly wrapped nanoscale $\mathrm{MgH}_{2}$ for efficient hydrogen storage cycling performances with extreme high gravimetric and volumetric capacities. Nano Energy 2019, 61, 540-549. [CrossRef]

40. Zhang, X.L.; Liu, Y.F.; Zhang, X.; Hu, J.J.; Gao, M.X.; Pan, H.G. Empowering hydrogen storage performance of $\mathrm{MgH} 2$ by nanoengineering and nanocatalysis. Mater. Today Nano 2020, 9. [CrossRef]

41. Amira, S.; Huot, J. Effect of cold rolling on hydrogen sorption properties of die-cast and as-cast magnesium alloys. J. Alloys Compd. 2012, 520, 287-294. [CrossRef]

42. Jorge, A.M.; de Lima, G.F.; Triques, M.R.M.; Botta, W.J.; Langdon, T.G. Correlation between hydrogen storage properties and textures induced in magnesium through ECAP and cold rolling. Int. J. Hydrog. Energy 2014, 39, 3810-3821. [CrossRef]

43. Kumar, G.; Lodh, A.; Jaiveer, S.; Singh, R.K.; Srivastava, D.; Dey, G.K.; Samajdar, I. Experimental characterization and finite element modeling of through thickness deformation gradient in a cold rolled zirconium sheet. CIRP J. Manuf. Sci. Technol. 2017, 19, 176-190. [CrossRef]

44. Suryanarayana, C. Mechanical alloying and milling. Prog. Mater. Sci. 2001, 46, 1-184. [CrossRef]

45. El-Eskandarany, M.S. Mechanical Alloying, Energy Storage, Protective Coatings, and Medical Applications, 3rd ed.; Elsevier: Oxford, UK, 2020.

46. El-Eskandarany, M.S. Metallic glassy $\mathrm{Ti}_{2} \mathrm{Ni}$ grain-growth inhibitor powder for enhancing the hydrogenation/ dehydrogenation kinetics of $\mathrm{MgH}_{2}$. RSC Adv. 2019, 9, 1036. [CrossRef]

47. El-Eskandarany, M.S.; Al-Ajmi, F.; Banyan, M. Mechanically-induced catalyzation of $\mathrm{MgH}_{2}$ powders with $\mathrm{Zr}_{2} \mathrm{Ni}$-ball milling media. Catalysts 2019, 9, 382. [CrossRef]

48. El-Eskandarany, M.S.; Shaban, E.; Al-Halaili, B. Nanocrystalline $\beta-\gamma-\beta$ cyclic phase transformation in reacted ball milled $\mathrm{MgH}_{2}$ powders. Int. J. Hydrog. Energy 2014, 39, 12727-12740. [CrossRef]

49. El-Eskandarany, M.S.; Shaban, E.; Al-Shemmiri, A. Integrated $\mathrm{Ni} / \mathrm{Nb}_{2} \mathrm{O}_{5}$ nanocatalytic agent dose for improving the hydrogenation/dehydrogenation kinetics of reacted ball milled $\mathrm{MgH}_{2}$ powders. J. Hydrog. Energy 2014, 39, 21097-21106. [CrossRef]

50. Huot, J.; Tousignant, M. Effect of cold rolling on metal hydrides. Mater. Trans. 2019, 60, 1571-1576. [CrossRef]

(C) 2020 by the authors. Licensee MDPI, Basel, Switzerland. This article is an open access article distributed under the terms and conditions of the Creative Commons Attribution (CC BY) license (http://creativecommons.org/licenses/by/4.0/). 